LBL -28810

DE91 004132

\title{
Exploratory Simulations of Multiphase Effects in Gas Injection and Ventilation Tests in an Underground Rock Laboratory
}

\author{
Stefan Finsterle \\ ETH Zürich, Switzerland \\ Erica Schlueter and Karsten Pruess \\ Earth Sciences Division \\ Lawrence Berkeley Laboratory \\ University of California \\ Berkeley, Californi? 94720
}

Versuchsanstalt für Wasserbau, Hydrologie und Glaziologie,

June 1990

\section{MASTER}

This work was supported by the Manager, Chicago Operations, Repository Technology Program, Repository Technology and Transportation Division, of the U.S. Department of Energy under Contract No. DEAC03-76SF00098 and by the Swiss National Cooperative for the Storage of Nuclear Waste (NAGRA). 


\section{Preface}

This report is one of a series documenting the results of the Nagra-DOE Cooperative (NDC-I) research program in which the cooperating scientists explore the geological, geophysical, hydrological, geochemical, and structural effects anticipated from the use of a rock ntass as a geologic repository for nuclear waste. This program was sponsored by the U. S. Department of Energy (DOE) through the Lawrence Berkeley Lahoratory (LBL) and the Swiss Nationale Genossenschaft fur die Lagerung radioaktiver Abfalla (Nagra) and concluded in September 1989. The principal investigators are Jane C. S. Long, Ernest L. Majer, Karsten Pruess, Kenzi Karasaki, Chalon Carnahan and Chin-Fu Tsang for LBL and Piet Zuidema, Peter Blthmling, Peter Hufschmied and Stratis Vomvoris for Nagra. Other participants will appear as authors of the individual reports. Technical reports in this series are listed below.

1. Determination of Fracture Inflow Parameters with a Borehole Fluid Conductivity Logging Method by Chin-Fu Tsang, Peter Hufschmied, and Frank V. Hale (NDC-1, LBL-24752).

2. A Code to Compute Borehole Fluid Conductivity Profiles with Multiple Feed Points by Frank V. Hale and Chin-Fu Tsang (NDC-2, LBL-24928; also NTB 88-21).

3. Numerical Simulation of Alteration of Sodium Bentonite by Diffusion of Ionic Groundwater Components by Janet S. Jacobsen and Chalon L. Carnahan (NDC-3, LBL-24494).

4. P-Wave Imaging of the FRI and BK Zones at the Grimsel Rock Laboratory by Ernest L. Majer, John E. Peterson Jr., Peter Bltumling, and Gerd Sattel (NDC-4, LBL-28807).

5. Numerical Modeling of Gas Migration at a Proposed Repository for Low and Intermediate Level Nuclear Wastes at Oberbauenstock, Switzerland by Karsten Pruess (NDC-5, LBL-25413).

6. Analysis of Well Test Data from Selected Intervals in Leuggern Deep Borehole - Verification and Application of PTST Method by Kenzi Karasaki (NDC-6, LBL-27914).

7. Shear Wave Experiments at the U. S. Site at the Grimsel Laboratory by Ernest L. Majer, John E. Peterson Jr., Peter Bltbmling, and Gerd Sattel (NDC-7 LBL-28808).

8. The Application of Moment Methods to the Analysis of Fluid Electrical Conductivity Logs in Boreholes by Simun Loew, Chin-Fu Tsang, Frank V. Hale, and Peter Hufschmied (NDC-8, LBL28809).

9. Numerical Simulation of Cesium and Strontium Migration through Sodium Bentonite Altered by Cation Exchange with Groundwater Components by Janet S. Jacobsen and Chalon L. Carnahan (NDC-9, LBL-26395).

10. Theory and Calculation of Water Distribution in Bentonite in a Thermal Field by Chalon L. Carnahan (NDC-10, LBL-26058).

11. Prematurely Terminated $\mathbf{s}^{1} \mathrm{\lambda g}$ Tests by Kenzi Karasaki (NDC-11, LBL-27528).

12. Hydrologic Characterization of Fractured Rocks -- An Interdisciplinary Methodology by Jane C. S. Long, Ernest L. Majer, Stephen J. Martel, Kenzi Karasaki, John E. Peterson Jr., Amy Davey, and Kevin Hestir, (NDC-12, LBL-27863).

13. Exploratory Simulations of Multiphase Effects in Gas Injection and Ventilation Tests in an Underground Rock Laboratory by Stefan Finsterle, Erika Schlueter, and Karsten Pruess (NDC-13, LBL28810).

14. Joint Seismic, Hydrogeological, and Geomechanical Investigations of a Fracture Zone in the Grimsel Rock Laboratory, Switzerland by Ernest L. Majer, Larry R. Myer, John E. Peterson Jr., Kenzi Karasaki, Jane C. S. Long Stephen J. Martel, Peter Bllumling, and Stratis Vomvoris (NDC-14, LBL27913).

15. Analysis of Hydraulic Data from the MI Fracture Zone at the Grimsel Rock Laboratory, Swituerland by Amy Davey, Kenzi Karasaki, Jane C.S. Long, Martin Landsfeld, Antoine Mensch, and Stephen J. Martel (NDC-15, LBL-27864).

16. Use of Integrated Geologic and Geophysical Information for Characterizing the Structure of Fracture Systems at the US/BK Site, Grimsel Laboratory, Switzerlarid by Stephen J. Martel and John E. Peterson Jr. (NDC-16, LBL-27912). 


\section{CONTENTS}

1. Introduction 1

2. Idealized Vertical Section Through FRI Zone, Grimsel Rock Laboratory 3

2.1. Problem Specification 4

2.2 Results 6

2.2.1. Pressures 6

$\begin{array}{ll}2.2 .2 \text {. Flow rates } & 7\end{array}$

2.2.3. Gas saturation $\quad 8$

2.2.4. Comparison of initial and final hydraulic test 8

2.3. Conclusions 10

3. Radial Gas Flow in a Fracture with Permeable Rock Matrix 11

3.1. Problem Specification 11

3.2. Results and Discussion 13

4. Multiphase Effects in Ventilation Tests 15

4.1. Gaseous Diffusion of Vapor and Air (Binary Diffusion) 15

4.1.1. Binary diffusion under single-phase conditions $\quad 16$

4.1.2. Binary diffusion under two-phase conditions 17

4.2. Capillary Pressures Initiated by Binary Diffusion 18

5. Discussion and Conclusions 20

$\begin{array}{ll}\text { Acknowledgement } & 20\end{array}$

References $\quad 21$

Text Figures $\quad 23$ 


\section{INTRODUCTION}

The "Nationale Genossenschaft für die Lagerung radioaktiver Abfälle" (NAGRA) of Switzerland has been investigating the suitability of Valanginian marl among other types of rock as a potential host rock for a repository for low and intermediate level nuclear wastes. Two candidate Valanginian marl sites have been selected for site investigations. At the Oberbauenstock site, a first phase of field investigations in 1987 involved drilling of three boreholes from the Seelisberg highway tunnel into a potential repository siting area. At the Wellenberg site, which is located approximately $12 \mathrm{~km}$ from Oberbauenstock, investigations of the Valanginian marl will start in 1990 with the drilling of several boreholes from the surface. Concerns about two-phase flow effects arose when the Oberbauenstock site investigations revealed the presence of natural gas (mainly methane) in the Valanginian marl.

A nuclear waste repository will contain large amounts of concrete, metals, and organic materials in contact with groundwater (NGB 85-07). Detailed studies have indicated that corrosion of the metals and microbial degradation of the organic materiais will evolve large amounts of gas (NGB 85-07; Neretnieks, 1985; Rasmuson and Elert, 1986; Wiborgh, Hoeglund, and Pers, 1986), the chief constituents being hydrogen, methane, and carbon dioxide. The expected gas release raises several concerns (Pruess, 1990). Increases in pore fluid pressures could endanger the integrity of the engineered barriers, alter natural groundwater level, and promote the migration of dissolved or volatile species.

The natural and repository-induced gas releases necessitate the development of methods for testing, analyzing and simulating two-phase flow behavior in fractured rock masses. It is with that objective in mind that the simulation studies discussed in this report were undertaken. In addition, they provide specific examples upon which the mutual transfer of technical know-how and the assessment/improvement of existing numerical codes could be facilitated. 
Two separate studies were conducted to aid in the design of gas injection tests at the "FRI zone" of the Grimsel rock laboratory. The actual flow geometry in these tests would be three-dimensional; however, the complexity of two-phase effects and the spatial resolution required for adequate representation dictated the use of two-dimensional approximations in the present exploratory simulations. Two complementary models were investigated, namely, an idealized vertical cross section through the FRI zone (see Section 2), and a radially symmetric gas injection system with interflow between fractures and a tight rock matrix (see Section 3).

Simulation studies of multiphase flow effects that could play a role in the so-called "ventilation tests" are also presented (Section 4). Such tests aim at quantifying the average permeability of a large rock mass around an excavation by monitoring the rate at which formation waters enter the zone of low (ambient) pressure created by the excavation (Wilson et al., 1981). Ventilation with air of less than 100\% humidity is used in these tests as a convenient means for conveying the incoming moisture to a measuring device. However, mini-ventilation tests conducted by NAGRA have cast doubt on the validity of the idealized view of ventilation as a merely passive conveyor of moisture. Effects such as differential drying of portions of drift walls have been observed at Grimsel, which suggest that ventilation may induce two-phase flow effects in the host rock. Such effects would impact the rate of water flow towards the pressure sink, and would affect design and analysis of ventilation experiments for evaluation of macropermeability.

All caiculations presented in this report were made with the simulation program "TOUGH", which describes two-phase flow of water and air, and heat flow, in porous and fractured media (Pruess, 1987). 


\section{IDEALIZED VERTICAL SECTION THROUGH FRI ZONE, GRIMSEL ROCK LABORATORY}

The field activities performed at Oberbauenstock showed that the presence of natural gas (mainly methane) in the Valanginian marl may have affected the hydrogeologic measurements significantly (Kennedy and Davidson, 1988). In the perspective of investigating the same host rock at Wellenberg it has been proposed to conduct a series of controlled gas experiments at the Grimsel Rock Laboratory (FLG) in order to gain some additional experience in performing and interpreting hydraulic tests in a two-phase gasliquid system.

The objective of the testing phase is to perform several tests under different but defined conditions. Three test steps are foreseen:

- Perform initial hydraulic tests in order to determine the existing hydraulic properties of the fully liquid-saturated feature;

- Create a two-phase system by injecting gas and then conduct a series of gas injection and extraction tests within this two-phase zone;

- Perform final hydraulic tests, following the same procedure as the initial tests, to determine the hydraulic characteristics in the presence of gras.

The results of the three test steps will be compared in order to assess the appropriateness and the limits of the single-phase interpretation methodology in a complex twophase environment (see also Finsterle, 1989).

The objective of the design calculations presented herein is to provide a first guess on pressure responses and flow rates that have to be expected during the test. These informations also allow to design the test equipment. Design calculations may help to plan and modify the location, sequence, and duration of each test step. 


\subsection{Problem Specification}

The gas test site is located at the FRI (Fracture Rock Investigation) zone. The fracture zone of interest is the $\mathrm{S} 1$ feature which will be modeled as a two-dimensional vertical section through laboratory tunnel, interval 13.1 , interval 10.2 , interval I1.2, and main access tunnel (see Figures 1 and 2). Injection will be made in interval I1.2. Interval 10.2 and $13 . i$ are monitoring wells. The specifications of the flow problem are given in Table 1; the computational grid and simulated initial pressure field are shown in Figure 3.

After several simulation runs with TOUGH and in consideration of other aspects (such as the time required to change equipment, working time etc.) the following test sequence was found to be appropriate (Lavanchy, 1989):

- Initial hydraulic test:

. $4 \mathrm{~h}$ constant pressure water injection at 20 bars

. about 1 week recovery

- Creation of gas bubble:

. $10 \mathrm{~h}$ constant pressure air injection at 20 bars

. 12 h shut-in recovery

. 1 h extraction

. $22 \mathrm{~h}$ constant pressure air injection at 20 bars

. 31 h shut-in recovery

. 24 h extraction

. $60 \mathrm{~h}$ shut-in recovery

- Final hydraulic test:

- $4 \mathrm{~h}$ constant pressure water injection at 20 bars

. shut-in recovery 
Table 1. Specifications of the idealized vertical section through the FRI zone at the Grimsel rock laboratory

Model domain (see Figures 2 and 3)

two-dimensional, vertical

lines $\left(A-A^{\prime}\right)$ and $\left(B-B^{\prime}\right)$ in Figure 2 define symmetry axes since borehole BoFR

87.001 is selected as the injection well and gravity is being neglected; only one quarter is modeled

fracture extending to laboratory and main access tunnel, respectively

computation ‘. grid: 192 grid blocks, 361 connections

\section{Formation properties}

homogeneous, isotropic

permeability: $\quad 2.0 \cdot 10^{-16} \mathrm{~m}^{2} \quad(0.2$ millidarcy $)$

thickness: $\quad 0.05 \mathrm{~m}$

porosity: $\quad 1 \%$

\section{Relative permeability}

liquid phase $\mathrm{k}_{\mathrm{rl}}=\mathrm{S} *^{4}$

gas phase $\mathrm{k}_{\mathrm{rg}}=\left(1-\mathrm{S}^{*}\right)^{2} \cdot\left(1-\left[\mathrm{S}^{*}\right]^{2}\right) \quad($ Corey $)$

where

$$
\begin{aligned}
& S^{*}=\left(S_{1}-S_{1 r}\right) /\left(1-S_{l r}-S_{g r}\right) \\
& S_{l r}=0.3 \\
& S_{g r}=0.05
\end{aligned}
$$

Gravity and capillary pressures: neglected

\section{Boundary conditions}

upper: $\quad$ constant pressure 3 bars (based on results at MI zone (Herzog 1989)) left: constant pressure between 1 bar (tunnel) and 3 bars (upper boundary). These values as well as the initial pressure field have been calculated by mears of an initial TOUGH simulation run to steady state.

lower/right: no flow (symmetry). 


\section{Initial conditions}

temperature: $10^{\circ} \mathrm{C}$

pressure: $\quad$ steady state pressure field as shown in Figure 3

saturation: the entire domain (except the tunnel) is initially fully water saturated

\section{Injection fluid}

fully vapor saturated air at constant pressure of 20 bars

\subsection{Results}

We first consider the test sequence where a gas bubble is created. We then proceed to compare the initial and final hydraulir 'ests.

\subsubsection{Pressures}

Figure 4 shows the pressures expected in the three boreholes intersecting the S1 feature, as a function of time:

- Injection well (BoFR 87.001):

Pressures are kept at 20 bars for 10 hours. During shut-in recovery, the pressures decrease very slowly due to large wellbore volume and the high compressibility of the gas. We open the borehole to atmospheric pressure for one hour. The same sequence is then repeated followed by the final shut-in period, where the pressures again increase to the formation pressures under steady state conditions.

- Observation wells (BoGA 89.001 and BoFR 87.003):

During the gas injection periods, the pressures in the observation wells increase faster compared to a water injection test. Note, that the pressure build-up is slightly affected by the relatively large volume of the boreholes even if this borehole is fully liquid saturated. The higher pressure response in the observation wells can be explained considering the pressure loss in the gas phase (which is about 75 times smaller than the one in the liquid phase due to the lower viscosity of gas), and the fact that the flow rates are higher when injecting gas instead of water. while changing from a gas-liquid system to a system with high gas contents at late times. 
In Figure 5 the pressures after each test step are drawn along the horizontal line between the tunnel and injection well. The test sequence leads to a rather complicated pressure field with changing gradients and flow directions.

\subsubsection{Flow rates}

Figure 6 shows the flow rates being injected or extracted. In Figure 7 the total gas mass and total gas volume in the formation as plotted as a function of time. They do not include the amount of gas needed to compress the air in the injeciion well from 1 to 20 bars (approximately $0.272 \mathrm{~kg}$ ). The same amount of air will be released instantaneously when opening the borehole for extraction. The gas flow rates during the first injection period show a slight increase after the first sharp drop. During shut-in recovery, the very large volume of the well assures continual gas injection as the gas in the well expands by decompression; Figure 6 shows that irjection rates hardly decrease. Upon opening the borehole, both water and gas flow back to the well in about the same amount (in terms of mass). After 1 hour of extraction, about $15 \%$ of the injected gas has been recovered. The peak rate at the beginning of the second injection period is slightly below the first one $(88.0 \mathrm{mg} / \mathrm{s}$ versus $101.0 \mathrm{mg} / \mathrm{s})$ due to the higher pressure (and thus lower gradient) around the borehole, even though the relative permeability is higher due to the higher gas saturation at this time. Subseque:itly the more or less constant gas flow rate is about two times larger than during the first injection period $(1.6 \mathrm{mg} / \mathrm{s}$ versus $(0.8 \mathrm{mg} / \mathrm{s})$ due to the higher relative permeability. After the second recovery period, a total air mass of about $0.225 \mathrm{~kg}$ has been injected. The total gas volume in the formation has reached about 12.5 1. At a porosity of 0.01 and an average gas saturation of approximately $20 \%$ (see below; Fig. 8), the injected gas plume has swept a formation volume of $12.5 /(0.01 \times 0.2)=$ 6250 l. Comparing the second extraction period with the first one, gas flow rates are now larger than liquid flow rates indicating that the gas saluration (and therefore relative permeability to gas) around the well has increased during the second injection period. 
During the final extraction and shut-in recovery, the gas volume continues to increase even though the total gas mass is reduced to about $0.105 \mathrm{~kg}$. This is a result of the fact that the pressure decay allows the gas to expand.

\subsubsection{Gas saturation}

The gas saturation along a line between the tunnel and BoFR 87.001 are illustrated in Figure 8. Because the gas saturation is not only a function of the injected mass of air but is also strongly related to the pressure field, an interpretation of the curves drawn in Figure 8 is difficult. It might be surprising that the gas saturation hardly exceeds $30 \%$ even close to the injection well. We do not see a piston-like displacement of immiscible fluids with a sharp front between the two phases, leading to a gas bubble with a well defined radius. The extension of the gas bubble (defined as the zone with two phases) is therefore dependent on the choice of the relative permeability functions.

\subsubsection{Comparison of initial and final hydraulic test}

A series of initial hydraulic tests will be performed in the FRI zone before creating a gas bubble as described in the previous section. The same series of tests (called final hydraulic tests) will then be conducted and the results compared with the initial ones. In this study we only consider a constant pressure water injection test for four hours followed by a recovery period.

The pressure respc.ises in the injection well and observation wells are drawn for ine initial hydraulic test in Figure 9, and for the final hydraulic test in Figure 10. The difference between the two figures is quite dramatic. The propagation of a pressure pulse is invere ely proportional to the compressibility of the fluid. During the final hydraulic test, the pressure pulse does not propagate to the observation wells; in fact, we hardly see a pressure reaction in the two observation wells. During recovery, the pressure in the injection well stays at a higher level due to the large storage of the gas filled pores in the formation. 
The water flow rates are a function of the pressure gradient, the relative pernieability, and the compressibility (storage) of the fluid around the injection borehole. Injecting water into a gas bubble, the pressure gradient remains steep for a longer time due to the gas compressibility and the difference in fluid viscosity. The injected water does not need to displace formation water but only has to compress the gas bubble. At the same time the relative permeability to liquid increases. However, for the considered times the decrease in the permeability does not seem to affect the flow rate which during the final hydraulic test is much higher than during the initial one (Figure 11).

The straight-line method of Jacob and Lohmann is now applied to both the initial and the final hydraulic test. The method allows to determine transmissivity and storativity given the flow rates of a constant head injection test:

$$
T=\frac{2.303}{4 \cdot \pi \cdot s_{w} \cdot \beta} ; \quad S=\frac{2.250 \cdot T \cdot t_{0}}{r_{w}^{2}}
$$

with

$$
\beta=\frac{\Delta(1 / q)}{\Delta \log (t)} ; \quad t_{0}=t \quad \text { for }(1 / q)=0.0 ; \quad s_{w}=\frac{p_{\text {inj }}-p_{0}}{\rho \cdot g}
$$

The straight-line approximation of the curve $1 / \mathrm{q}$ versus $\log (\mathrm{t})$ provides two parameters: the intersection with the $\log (t)$ axis (represented by $t_{0}$ ) determines storativity; the slope (represented by $\beta$ ) determines transmissivity. Table 2 compares the results of the initial and final hydraulic tests obtained by the Jacob-Lohmann-Plot (Figure 12). The transmissivity evaluated in a single phase liquid environment during the initial hydraulic test corresponds to the value used in the numerical model. The calculations show that the transmissivity obtained in the two phase system is nearly the same, whereas the storativity has increased by a factor of 440 . It seer that the effects of the characteristics altered by the presence of the "gas bubble" cance. each other (i.e., lower relative permeability but higher pressure gradient and higher fluid compressibility). This is reasonable, if one considers that in the method of Jacob and Lohmann the evaluation of the transmissivity is restricted to the second part of the curve where most of the formation in the vicinity of the borehole is again saturated by a single phase. 


\begin{tabular}{|c|c|c|}
\hline & $\begin{array}{c}\text { initial } \\
\text { byddraulic test }\end{array}$ & $\begin{array}{c}\text { final } \\
\text { hydraulic test }\end{array}$ \\
\hline regression: $(1 / \mathrm{q})=\mathrm{a}+\mathrm{l}$ & & \\
\hline a $\quad[\mathrm{s} / \mathrm{mnl}]$ & 3.7800 & -27.97 \\
\hline b $[1 / \mathrm{ml}]$ & 10.4000 & 11.95 \\
\hline$r \quad[-]$ & 0.9964 & 0.9998 \\
\hline$b \quad[s]$ & 0.4330 & 219.100 \\
\hline Transmissivity $\left[\mathrm{m}^{2} / \mathrm{s}\right]$ & $1.0006 \cdot 10^{-13}$ & $0.8710 \cdot 10^{-10}$ \\
\hline$S / s_{\text {initial }}$ & 1.0 & 440.5 \\
\hline
\end{tabular}

Table 2: Evaluation of Jacob-Lohmann-Hlots

\subsection{Conclusions}

The design calculatio f $f$ the gas test show that it should be possible, by means of gas injection, to create a region with a significant gas content so that two-phase phenomena can be studied in subsequent tests. The test sequence and duration of each test step as proposed in the work program (Lavanchy, 1989) seem to be reasonable. The gas flow rates and pressures would be measurable in-situ.

Note that the results presented in this report comprise the design calculations and are based on simplifying assumptions. Although, the choice of parameters appears to be reasonable for the FRI-zone, the results are also sensitive on parameters that are not well known. Therefore, the actual test program should be flexible in anticipation of effects and responses that deviate from the predicted ones.

The numerical simulation also indicates that absolute (saturated) permeability in a two-phase environment may be estimated using standard single-phase evaluation methods. 


\section{RADIAL GAS FLOW IN A FRACTURE WITH PERMEABLE ROCK MATRIX}

This problem was designed to explore possible operating conditions for gas injection tests in a fracture, with consideration of flow into an adjacent rock matrix of low permeability (Figure 13). The feasibility wi creating a two-phase zone of "significarit" extent was of particular interest.

\subsection{Problem Specification}

The specifications of the flow problem are given in Table 3; the computational grid is shown in Figure 14. Most parameters were provided by Andre:ws (1988); minor adjustments were made, as follows. At the initially specified gas injection rate of $10^{-4}$ $\mathrm{kg} / \mathrm{s}$, pressure at the injection point increased to large values in excess of 60 bars (Figure 15). The gas injection rate was therefore reduced by one order of magnitude, to $10^{-5}$ $\mathrm{kg} / \mathrm{s}$, which resulted in a more acceptable pressurization to near 20 bars (Figure 16). Relative permeabilities to liquid and gas were represented with Corey's functions (1954), instead of the originally specified Grant's functions (1977). Grant's liquid relative permeability is identical to Corey's, while his gas relative permeability is given by $\mathrm{k}_{\mathrm{rg}}=1$ $\mathrm{k}_{\mathrm{rl}}$, which is considerably larger than Corey's gas relative permeability (नigure 17). It was frequently assumed in the literature that for fractured media the constraint $k_{\mathrm{rg}}+\mathrm{k}_{\mathrm{rl}}=$ 1 is applicable; However, recent theoretical work has indicated that phase interference in fractures will generally be stronger than in porous media (Pruess and Tsang, 1989). Thus, Corey's functions are believed to be more realistic for the present problem.

Gravity and capillary pressure effects were neglected in the simulations, as they are expected to be small in comparison to pressure effects from gas injection. In the absence of gravity, the flow system is symmetric with respect to midplane of the fracture (see Figure 13), so that only one half of the system needs to be modeled. The numerical behavior of the flow system was simplified by specifying an initial gas saturation of $1 \%$ throughout. This avoids the highly non-linear phase transitions that would occur when a 
gas fronı invades a water-saturated medium. Irreducible (immobile) gas saturation was specifier. as $2 \%$ in the fractures, and $10 \%$ in the matrix, so that the initially present gas is immobile and will not cause unphysical effects.

T-ble 3. Parameters for dual-permeability fracture-matrix flow problem.

Model domain (see Figures 13 and 14) ${ }^{1}$

- radial symmetry

- two-dimensional (R-Z)

- well radius $0.10 \mathrm{~m}$

- discrete horizontal fracture, $9.02 \mathrm{~m}$ aperture matrix block extonding $10 \mathrm{~m}$ above and below fracture

\section{Formation properties}

$\begin{array}{llll}\text { domain } & \text { permeability } & \text { thickness } & \text { porosity } \\ \text { fracture } & 10 \mathrm{md} & 0.01 \mathrm{~m}^{1} & 50 \% \\ \text { matrix } & 10^{-4} \mathrm{md} & 10.0 \mathrm{~m} & 1 \%\end{array}$

\section{Relative permeability}

$$
\begin{array}{lll}
\text { liquid phase } & \mathrm{k}_{\mathrm{rl}}=\mathrm{S}^{*} & \\
\text { gas phase } & \mathrm{k}_{\mathrm{rg}}=\left(1-\mathrm{S}^{*}\right)^{2} \cdot\left(1-\left[\mathrm{S}^{*}\right]^{2}\right) & \text { (Corey) } \\
\mathrm{k}_{\mathrm{rg}}=1-\mathrm{k}_{\mathrm{rl}} & \text { (Grant) } \\
& \text { where } \mathrm{S}^{*}=\left(\mathrm{S}_{1}-\mathrm{S}_{\mathrm{lr}}\right) /\left(1-\mathrm{S}_{\mathrm{lr}}-\mathrm{S}_{\mathrm{gr}}\right) & \\
\mathrm{S}_{\mathrm{lr}}=0.3 & \\
\mathrm{~S}_{\mathrm{gr}}=0.02 \text { (fracture), } 0.1 \text { (matrix) } &
\end{array}
$$

Gravity and capillary pressures: neglected

\section{Boundary conditions}

fracture, outer:

1 bar

matrix (outer, top, inner): no flow

\section{Initial conditions}

pressure: $\quad 1$ bar

temperature: $\quad 10^{\circ} \mathrm{C}$ 
gas saturation: $1 \%$

\section{Injection}

air at rates of $10^{-4}$ and $10^{-5} \mathrm{~kg} / \mathrm{s}$, or shut-in

${ }^{1}$ because of symmetry, only half the fracture is modeled

\subsection{Results and Discussion}

Gas injection at $10^{-5} \mathrm{~kg} / \mathrm{s}$ proceeds until gas saturation has increased to absut $10 \%$ at a disunce of $10 \mathrm{~m}$ from the injection point. This is achieved after approximately 7 days in grid block AA9, which extends from 6.05 to $10.05 \mathrm{~m}$; see Figures $18-20$. Notice that at this time gas has penetrated only a few centimeters into the rocl: matrix, due to its very low permeability. Pressure buildup in response to gas injection is extremely rapid (see Figures 16 and 21 ), exceeding 12 bars at the injection point after only 23 seconds. The buildup levels off after a quasi-steady pressure of approximately 20 bars is reached. For Grant relative permeabilities the pressure buildup is considerably smaller, as expected (Figure 21), while the increase in gas saturation is slowed (Figure 22). Gas injection is stopped after 7 days, resulting in a initially rapid pressure decline which subsequently slows down considerably (Figures 21, 23). Injection is resumed after 114 days, at which time pressure recovery is approximately $90 \%$ complete (see Figure 21). A gas saturation of $50 \%$ at $10 \mathrm{~m}$ from the injection point is reached after approximately 5000 days (Figure 18). Subsequent shut-in of injection gives rise to an exceedingly slow pressure recovery.

It is of interest to compare the predicted pressurization and flow effects in the radial fracture model with those obtained before in the vertical model. In the radial model, the permeability-thickness product for the fracture is $10 \mathrm{md} \times 0.01 \mathrm{~m}=0.01 \mathrm{md}-\mathrm{m}$, and injection at a rate of $10^{-5} \mathrm{~kg} / \mathrm{s}=10 \mathrm{mg} / \mathrm{s}$ results in a pressurization to approximately 20 bars in the gas plume (Figure 16). The permeability-thickness product for the vertical fracture model was $0.2 \mathrm{md} \times 0.05=0.01 \mathrm{md}-\mathrm{m}$, or $1 / 10$ that of the radial model. Application of a constant gas pressure of 20 bars at the injection point resulted in a quasi- 
steady injection rate of approximately $1 \mathrm{mg} / \mathrm{s}$, which is consistent with the $10: 1$ contrast in permeability-thickness between the two models.

The dominant feature seen in all of the gas injection simulations is the very tight nature of the formation into which gas injection is made. Matrix permeability is extremely low, and the higher fracture permeability is available only in a very thin zone. This tightness causes a very strong pressure response to injection, as gas advances to displace formation water. The dominant cause of pressure buildup is single-phase flow of liquid water ahead of the displacement front, while pressure gradients level off in the invaded zone of larger gas saturation (see Figures 16 and 19). This behavior is easily explained in terms of the viscosity contrast between water and air. At $10^{\circ} \mathrm{C}$, water viscosity exceeds that of air by a factor of approximately $75\left(13.0 \times 10^{-4} \mathrm{~Pa} \mathrm{~s}\right.$ versus $0.176 \times 10^{-4} \mathrm{~Pa} \mathrm{~s}$; Vargaftik, 1975). Thus, displacement of water ahead of the invading gas front at the same volumetric rate as air displacement behind the front requires 75 times larger pressure gradients.

These simulation results are preliminary because the test case studied here is of a highly idealized and schematic nature. Important formation characteristics such as relative permeability and capillary pressure behavior are not known at the present time, and hypothetical assumptions had to be made. Assuming that the FRI test section at Grimsel is in fact as tight as specified in the present simulations, the gas injection rate should be restricted to $10^{-5} \mathrm{~kg} / \mathrm{s}$ or less to avoid excessive pressure buildup. Time scales involved in gas injection testing tend to be large, and the formation is being probed only over relatively small spatial scales of a few meters. Future calculations should explore the sensitivity of pressure and saturation response to possible ranges of formation parameters. Also, alternatively testing protocols should be examined to determine whether two-phase flow behavior of larger formation volumes can be probed within a reasonable time frame. One possible mode of operation might be to alternate between periods of gas injection and periods of well shut-in or production. The decrease in fluid pressures when injection is stopped would cause gas to expand, which would promote an increase in gas saturation and thereby enable gas to penetrate further into the rock. 


\section{MULTIPHASE EFFECTS IN VENTILATION TESTS}

In order to determine the large-scale hydrrulic permeability of the host rock, the water inflow to a tunnel and the hydraulic pressure distribution in the vicinity of the exc.vation are monitored. Due to the low outflow of moisture from a very tight rock, ventilation with dry air is used to convey the incoming moisture to a cooling trap while the water is condensed from the tunnel atmosphere. During the ventilation tests performed at the Grimsel rock laboratory, partial drying of portions of drift walls have been observed. In this chapter, conceptual models are discussed by means of computer simulations with the TOUGH simulator to study the possible impact of two-phase effects on the design and analysis of the ventilation experiments.

\subsection{Gaseous Diffusion of Vapor and Air (Binary Diffusion)}

Assuming that the air in the tunnel is kept dry by ventilation, a gradient of air humidity causes an exchange of air and vapor across the rock surface. The effect is known as binary diffusion and can be described as follows: If two gases of different molecular weight (air and vapor, $\mathrm{M}_{\mathrm{air}} \approx 28.96>\mathrm{M}_{\mathrm{vapor}} \approx 18.00$ ) are allowed to interdiffuse then a net flux of vapor from the more humid to the drier region and an equal and opposite net flux of air molecules will occur. Diffusion effects in porous media are complicated due to the complex geometry of the pore space; the flux expression used in TOUGH is as follows.

$$
\begin{aligned}
& F_{\text {bin.diff. }}^{\text {air }}=-F_{\text {bin.diff. }}^{\text {vapor }}=-D_{v a} \cdot \rho_{g} \cdot \nabla X_{g}^{\text {(air) }} \\
& \text { with } \\
& D_{\text {va }}=\tau \cdot \phi \cdot S_{g} \cdot D_{v a}^{0} \cdot \frac{P_{0}}{P}\left[\frac{T+273.15}{273.15}\right]^{\theta}
\end{aligned}
$$


where

$$
\begin{array}{ll}
F_{\text {bin.diff. }}^{\text {vair }} & =\text { diffusive mass flux of air }\left[\mathrm{kg} / \mathrm{m}^{2} \cdot \mathrm{s}\right] \\
F_{\text {bin.diff. }}^{\text {aapor }} & =\text { diffusive mass flux of vapor }\left[\mathrm{kg} / \mathrm{m}^{2} \cdot \mathrm{s}\right] \\
\rho_{\mathrm{g}} & =\text { gas density }\left[\mathrm{kg} / \mathrm{m}^{3}\right] \\
X_{\mathrm{g}}^{(\kappa)} & =\text { mass fraction of component } \kappa \text { in gas phase }\left(\mathrm{X}_{\mathrm{g}}^{\mathrm{vapor}}=1-\mathrm{X}_{\mathrm{g}}^{\mathrm{air}}\right) \\
\mathrm{D}_{\mathrm{va}} & =\text { vapor-air diffusion coefficient }\left[\mathrm{m}^{2} / \mathrm{s}\right] \\
\mathrm{D}_{\mathrm{va}}^{0} & =\text { parameter for diffusive vapor flux }\left[\mathrm{m}^{2} / \mathrm{s}\right] \\
\theta & =\text { parameter for temperature dependence of binary diffusion } \\
\phi & =\text { porosity }\left[\mathrm{m}^{3} / \mathrm{m}^{3}\right] \\
S_{\mathrm{g}} & =\text { gas saturation }\left[\mathrm{m}^{3} / \mathrm{m}^{3}\right] \\
\tau & =\text { tortuosity }\left[\mathrm{m} / \mathrm{m}^{3}\right]
\end{array}
$$

Two specific cases of binary diffusion are studied in a simple two-grid-block numerical experiment.

\subsubsection{Binary diffusion under single-phase conditions}

We model two separated grid blocks containing gas of different vapor content at an initial pressure of 1 bar. A porosity of 0.1 is chosen and the absolute permeability is equal $5.0 \times 10^{-17} \mathrm{~m}^{2}$. Grid block 1 is filled with dry air (air mass fraction in the gas phase is equal to 1.0), whereas the gas in grid block: is vapor saturated air $(100 \%$ relative humidity at $10^{\circ} \mathrm{C}$ and 1 bar corresponds to an air mass fraction of 0.99233 ). The situation is sketched in Figure 24. At time zero, the gas is allowed to interdiffuse. The diffusion process tends to equalize the air mass fraction in the two grid blocks. Air molecules are invading grid block 2, vapor is invading grid block 1 at the sarne mass rate. The air mass fraction in grid block 1 decreases, whereas the air mass fraction in grid block 2 increases to the average value of 0.99617 (Figure 25). Since the molecular weight of air is larger than the molecular weight of vapor, grid block 1 has a net gain in 
the number of gas molecules; as a result, the pressure in grid block 1 increases slightly and the pressure in grid block 2 decreases due to the same reason. Since the total number of molecules is large in comparison to the number of molecules being exchanged, the pressure change in the two grid blocks is nearly symmetric. The pressure gradient established by the diffusion process is dissipated by viscous flow of gas from grid block 1 to grid block 2. In the end, the system is in a uniform state of pressure and temperature; gas of different moisture has been exchanged.

\subsubsection{Binary diffusion under two-phase conditions}

We consider two separated grid blocks. A porosity of 0.1 is chosen and the absolute permeability is equal $5.0 \times 10^{-17} \mathrm{~m}^{2}$. Grid block 1 is filled with dry air (air mass fraction in the gas phase is equal to 1.0$)$. Grid block 2 contains two phases $\left(S_{g}=0.5\right)$. The liquid phase assures the air to be vapor saturated at any time (concept of instantaneous equilibrium). The situation is sketched in Figure 26.

At time zero, the gas is allowed to interdiffuse. Since a difference in air and vapor partial pressure is present, binary diffusion takes place. Vapor is invading grid block 1 , air is invading grid block 2 at the same mass rate. Gas pressure in grid block 2 starts to grow because the invading air molecules increase the air partial pressure, whereas vapor partial pressure is stabilized by vaporization, leading to a slight temperature drop (Figure 27). The gas pressure in grid block 1 also increases because the loss of air partial pressure is less than the gain in vapor partial pressure due to the difference in the molecular weights of the two components. In a tight rock, the pressure increase caused by binary diffusion cannot dissipate instantaneously by viscous flow of gas from grid block 2 back to grid block 1 . Therefore, the diffusive flow is counteracted by a Darcy flux, the pressure gradient being a function of permeability. The lower the permeability, the larger the pressure difference between the two grid blocks. This conclusion assumes that the diffusion coefficient is not dependent on permeability. Still, there might be a correlation between relative permeability and tortuosity, leading to reduced diffusion in partially saturated porous media. 
After about one hour, the air in grid block 1 is vapor saturated; condensation takes place and temperaiure in grid block 1 increases. Diffusive $\mathfrak{n}$ iux stops, because gas phase composition equilibrium is very nearly reached. Conductive and convective heat flux is not zero till temperature and pressure are in equilibrium.

The final state of the system can be described as follows. Pressures have increased by about $810 \mathrm{~Pa}$. This value is a function of the number of molecules being exchanged in relation to the total number of gas molecules in the system. The gas in both grid blocks is air of $100 \%$ humidity. Temperature has decreased by about $0.0016^{\circ} \mathrm{K}$. The net overall temperature drop is due to a finite net vaporization which put some additional mass into gas phase; its value is also a function of the systems heat capacity. Under two-phase conditions, thermal energy becomes pressure by phase change, mediated by binary diffusion.

\subsection{Capillary Pressures Initiated by Binary Diffusion}

In the vicinity of the excavation in the Grimsel Rock Laboratory, negative pressures (relatively to atmospheric pressure) have been observed in certain intervals indicating the existence of capillary forces. The underlying physical processes are conceptualized and modeled as follows:

We consider a one-dimensional horizontal column with a gas filled reservoir (representing the tunnel) attached to its left end. The column is initially fully liquid saturated and at a uniform pressure of 1 bar. Van Genuchten's relative permeability and capillary pressure functions are applied (Figure 28).

Since the air in the tunnel is not fully vapor saturated, binary diffusion takes place which allows the water in the pores to evaporate. The gas saturation in the first millimeters increases; a gas-liquid front propagates into the formation (Figure 29). Providing the rock permeability is low, water cannot refill the gas filled pore space fast enough, even if there was a pressure gradient toward the tunnel. After a certain time, the process is counteracted by capillary forces which tend to reduce the gas saturation by reducing the pressure in the liquid phase and therefore increasing the pressure gradient toward the 
tunnel. Liquid water is sucked to the gas-liquid front by capillary forces, evaporation takes place and water molecules flow to the tunnel by viscous and diffusive fiux of vapor.

Phase transition by evaporation is the only mechanism that allows the water molecules to leave the formation. Liquil water is always underpressured (relatively to the pressure in the turnel) due to capillarity, so there is no viscous liquid flux to the tunnel, whereas vapor follows the pressure in the gas phase which is increased due to the diffusion process (see Section 4.1.2.). Tn the other hand, binary diffusion is the only mechanism which allows air to invade, even though the pressure gradient in the gas phase is reversed. The initially fully liquid saturated formation dries out. 


\section{DISCUSSION AND CONCLUSIONS}

The preliminary modeling studies presented in this report have shown a complex phenomenology of multiphase behavior in gas injection and ventilation tests. The mathematical and numerical approaches used in the TOUGH simulator are shown to be sufficiently robust and flexible for scoping studies of two-phase water-gas flow in fractured rock. Application of these concepts for a more detailed interpretation of the mini-ventilation tests in Grimsel Test Laboratory appears quite promising. A principal limitation of practical applications at the present time is the lack of credible site-specific data. A close interaction between conceptual and numerical modeling on the one hand, and field test design and analysis on the other, will be required in future studies.

It appears that two-phase testing of initially water-saturated tight fractured rock masses will be a time-consuming process, and will be limited with respect to the formation volumes that can be probed. An important issue to be addressed in future testing is the characteristic curves (relative permeability and capillary pressures) of fractured rock masses. No experimental data are presently available on relative permeability behavior of rough-walled rock fractures. On a more fundamental level, there is the possibility that formation heterogeneities and flow instabilities in the displacement of a heavier, more viscous fluid (water) by a lighter fluid of lower viscosity (air or other gases) could cause gas to "finger" through portions of fractures, while bypassing other zones that would remain water-saturated. Thus, it is not clear to what extent continuum concepts such as relative permeability will be applicable to two-phase flow processes in fractures on different space and time scales.

\section{Acknowledgement}

This work was supported by NAGRA, Baden, Switzerland, and the U.S. Department of Energy under Contract No. DE-AC03-76SF(00)98. The authors gratefully acknowledge the technical guidance obtained from NAGRA through Drs. Charles McCombie, Piet Zuidema, Peter Hufschmied and Stratis Vomvoris. 


\section{References}

Andrews, R., 1988. Design/test calculations for two-phase flow in a dual-porosity, dualpermeability medium using TOUGH, Internal memorandum to NAGRA, Motor Columbus AG/INTERA Inc., Baden, Switzerland.

Corey, A.T., 1954. The interrelation betr ien gas and oil relative permeabilities. Producers Monthly, 38-41, November.

Finsterle, S., 1989. FLG: Design calculation for a gas test at Grimsel Rock Laboratory, Nagra Irterner Bericht NIB 89-62, Baden, Switzerland, July.

Grant, M.A., 1977. Permeability reduction factors at Wairakei, papaer 77-HT-52, presented at AICHE-ASME Heat Transfer Conference, Salt Lake City, Utah, August.

Herzog, F., 1989. Grimsel test site, Hydrologic modelling of the migration mite at the Grimsel test site - the steady state. Nagra Report NTB 89-16, Baden, Switzerland, July.

Kennedy', K.G., Davidson, L.M., 1989. Oberbauenstock (OBS) 1987: Results of the hydrogeological testing program OBS-1. Nagra Report NTB 88-03, Baden, Switzerland, February.

Lavanchy, J.-M., 1989. Felslabor Grimsel - Project HPA, Gas Testing - Phase 2, Work Program, Internal memorandum, COLENCO AG/INTERA Inc., Baden, Switzerland, July.

Neretnieks, I., 1985. Some aspects of the use of ircn canisters in deep lying repositories for nuclear waste, Nagra Report NTB 85-35, Baden, Switzerland, February.

NGB 85-07, 1985. Endlager für schwach. und mittelaktive Abfälle: Das System der Sicherheitsbarrieren, Nagra Report, Baden, Switzerland, January.

Pruess, K., 1990. Numerical modeling of gas migration at a proposed repository for low and intermediate level nuclear wastes at Oberbauenstock, Switzerland, Lawrence Berkeley Laboratory Report LBL-25413, NDC-5. 
Pruess, K., 1987. TOUGH user's guide, Nuclear Regulatory Commission, Report NUREG/CR-4645, June (also Lawrence Berkeley Laboratory Feport LBL-20700, Berkeley, Ca., June)

Pruess, K. and Tsang, Y.W., 1989. On relative permeability of rough-walled fractures, Lawrence Berkeley Laboratory Report LBL-26509, presented at the Fourteenth Annual Workshop on Geothermal Reservoir Engineering, Standford University, Standford, Ca., January.

Rasmuson, A. and Elert, M., 1986. The influence of gas flow on solute transport, Kemata AB, Stockholm, draft “eport to Nagra, Baden, Switzerland, October.

Vargaftik, N.B., 1975. Tables on the Thermophysical Properties (f Liquids a id Gases, Second Edition, John Wiley and Sons, New York.

Wiborgh, M., Höglund, L.O., and Pers, K., 1986. Gas formation in a L/ILW repository and gas transport in the host rock, Nagra Report NTB 85-17, Baden, Switzerland, December.

Wilson, C.R., Long, J.C.S., Galbraith, R.M., Karasaki, K., Endo, H.K., Dubois, A.O., McPherson, M.J., and Ramqvist, G., 1981. Geohydrological data from the macro-permeability experiment at Stripa, Sweden, Lawrence Berkeley Laboratory Report LBL-12520, March. 
$-23-$

TEXT FIGURES 


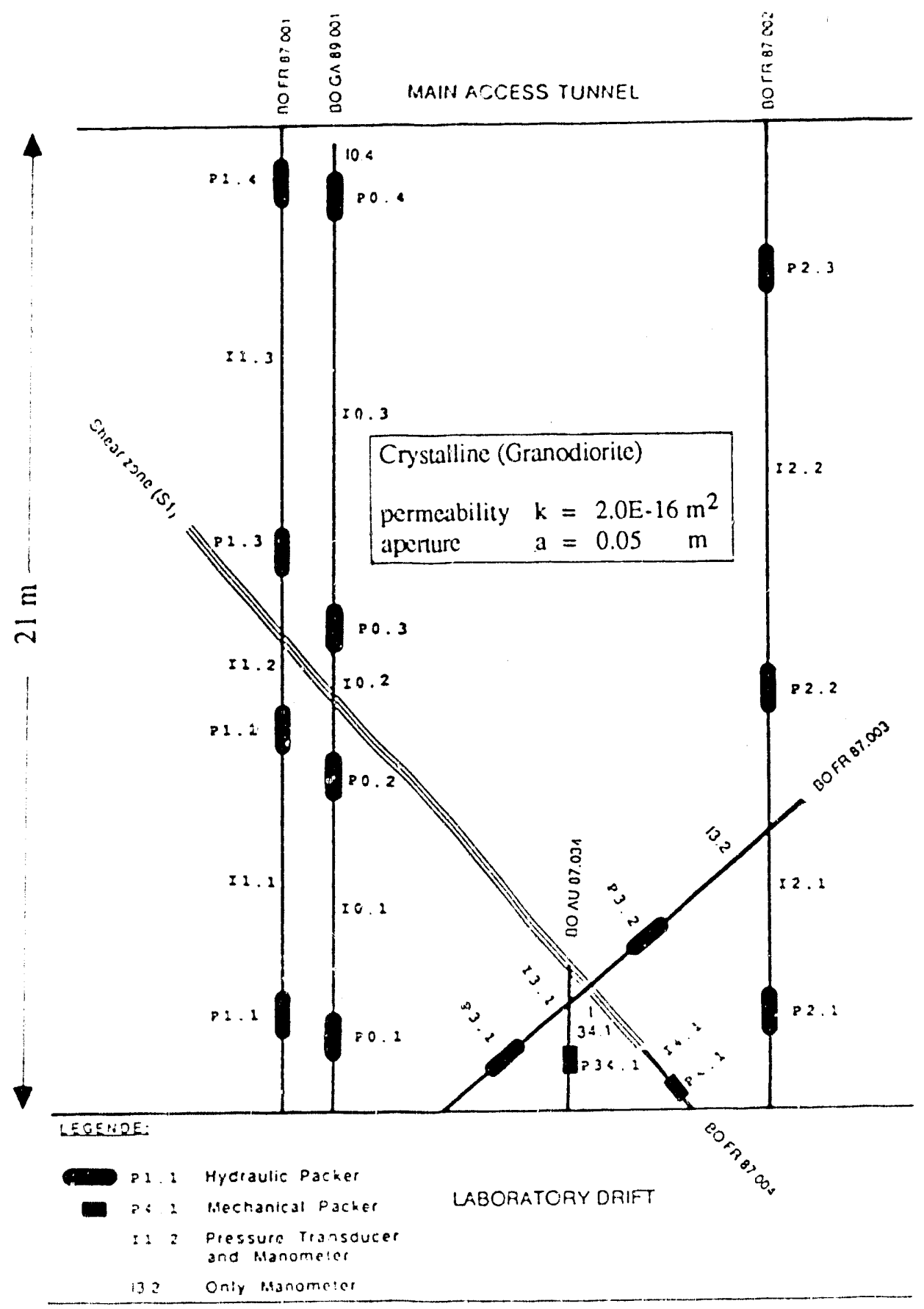

Figure 1: Projection to a horizontal plane of the test system configuration. 


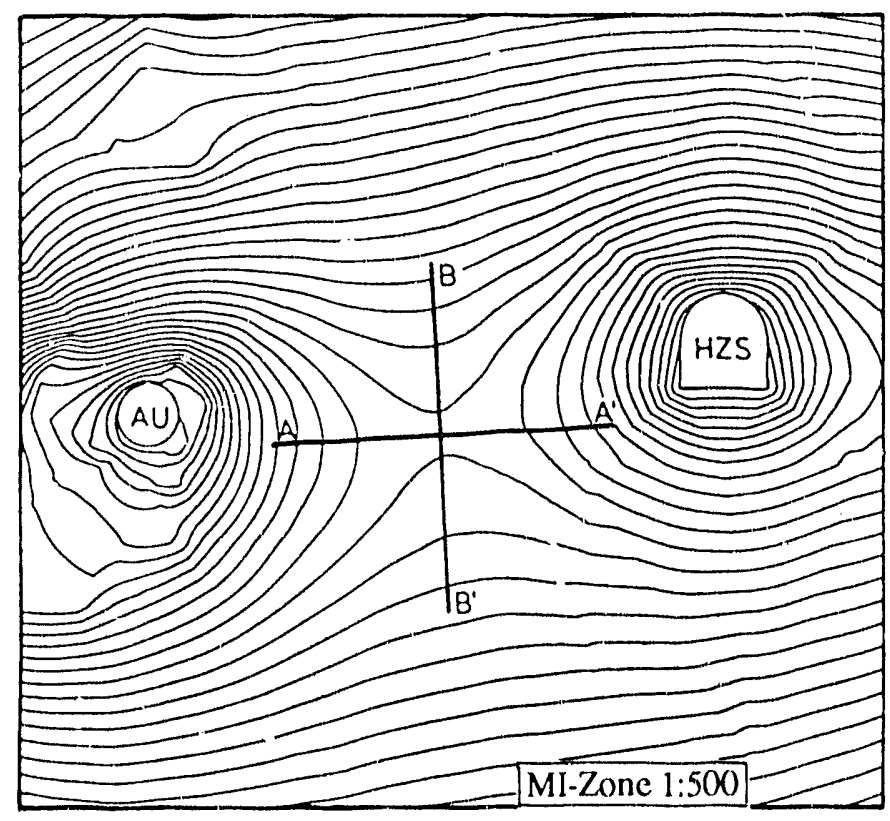

Figure 2a: Vertical section, symmetriy axis.

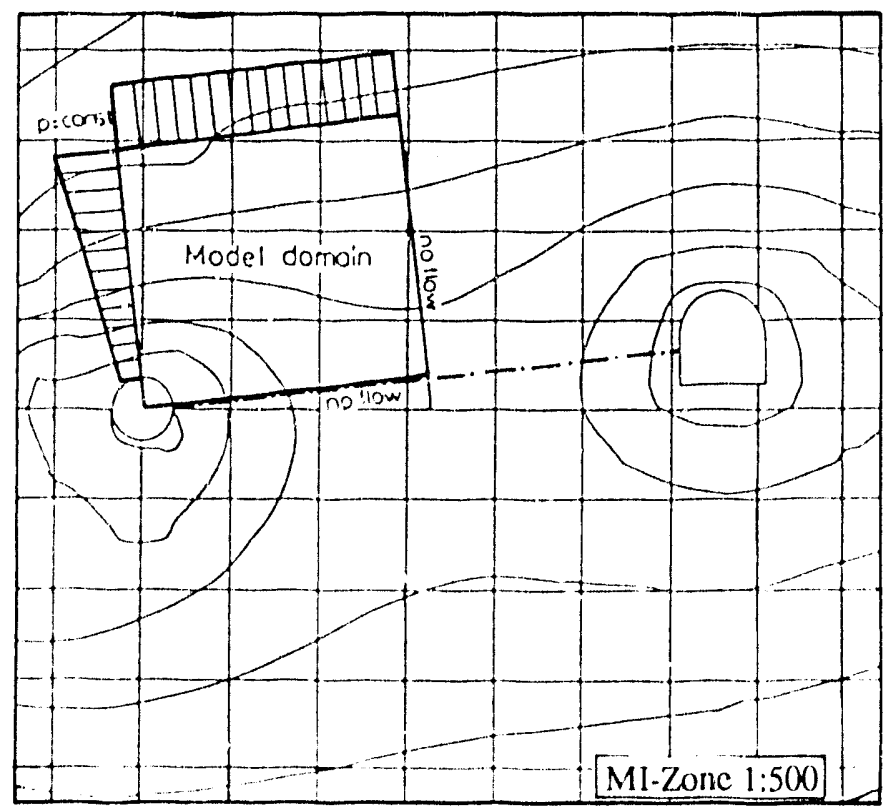

Figure 2b: Vertical section, simplifications. 


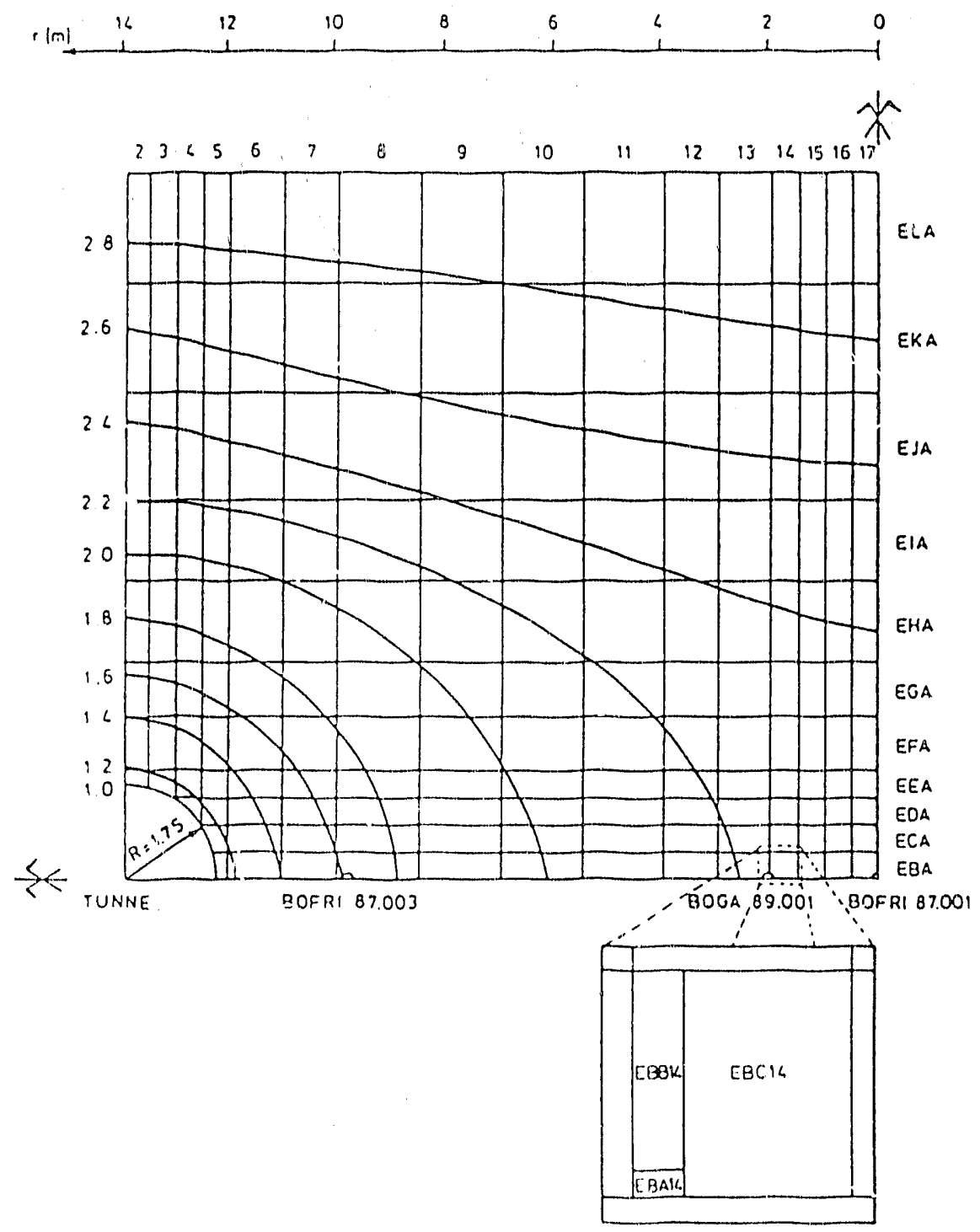

Figure 3: Finite difference grid, initial pressure field. 


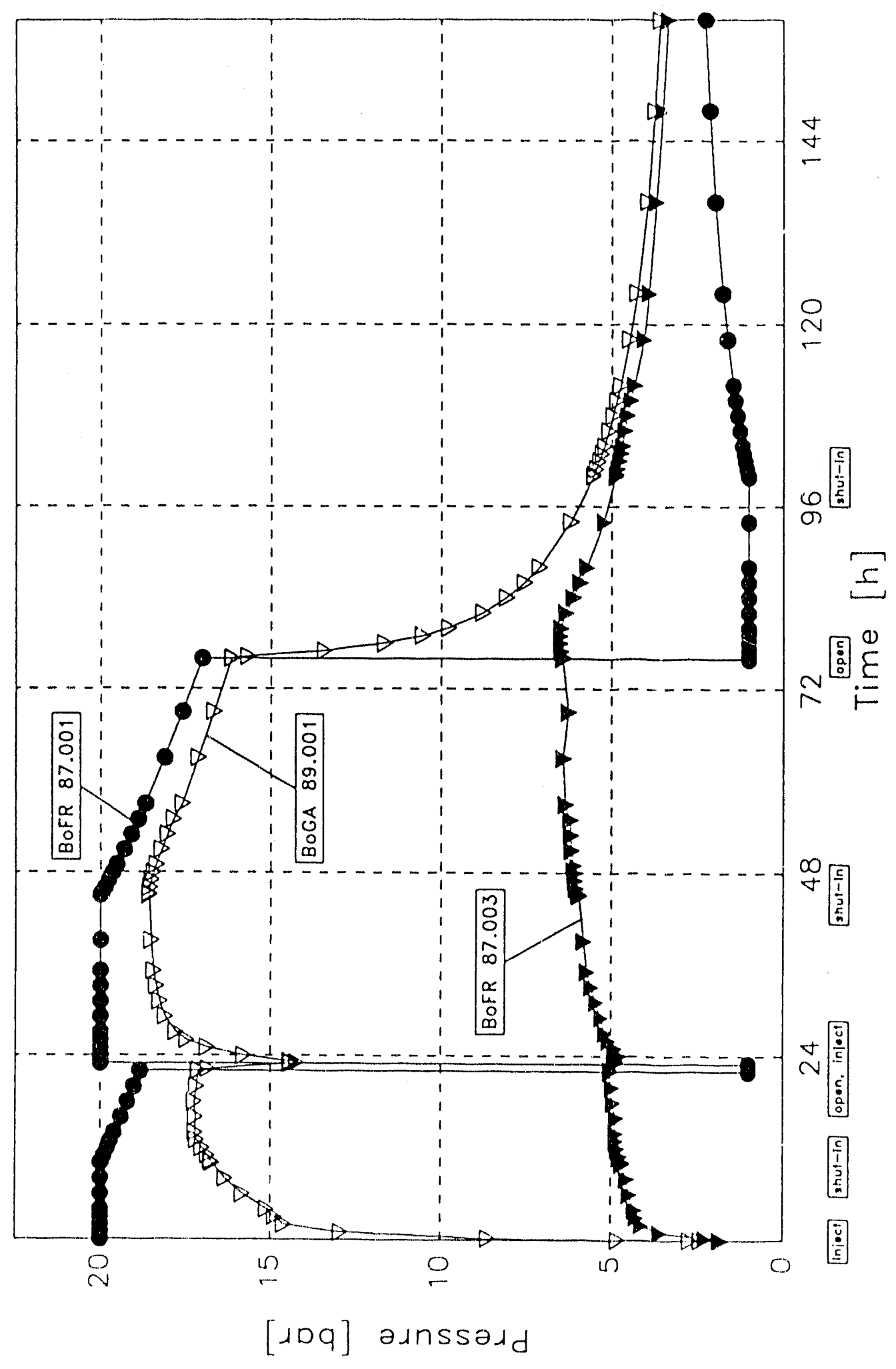

Figure 4: Predicted pressures in the injection and observation wells ats a function of time. 


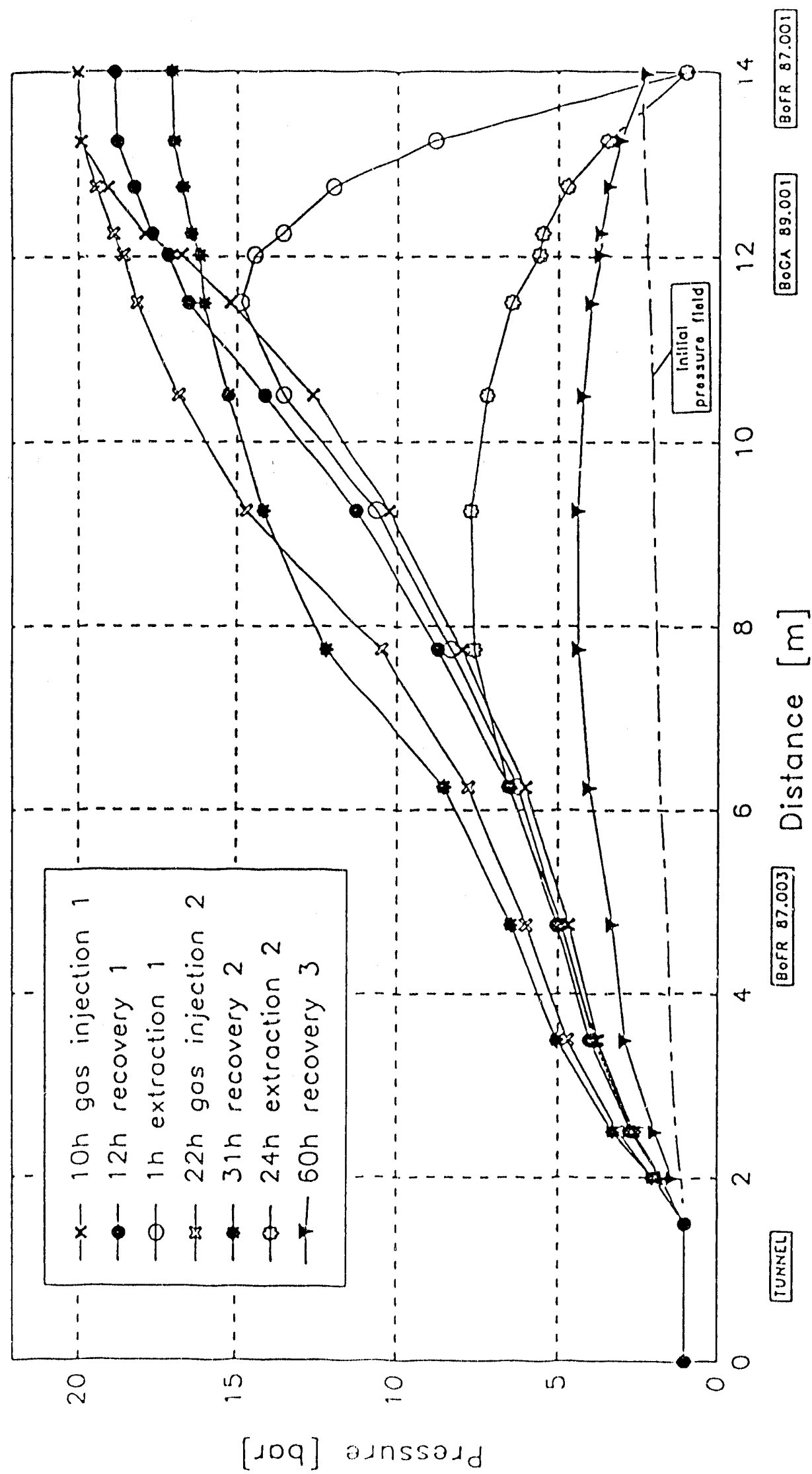

Figure 5: Predicted pressures along the horizontal line bctween the tunnel and injection well after each test step. 


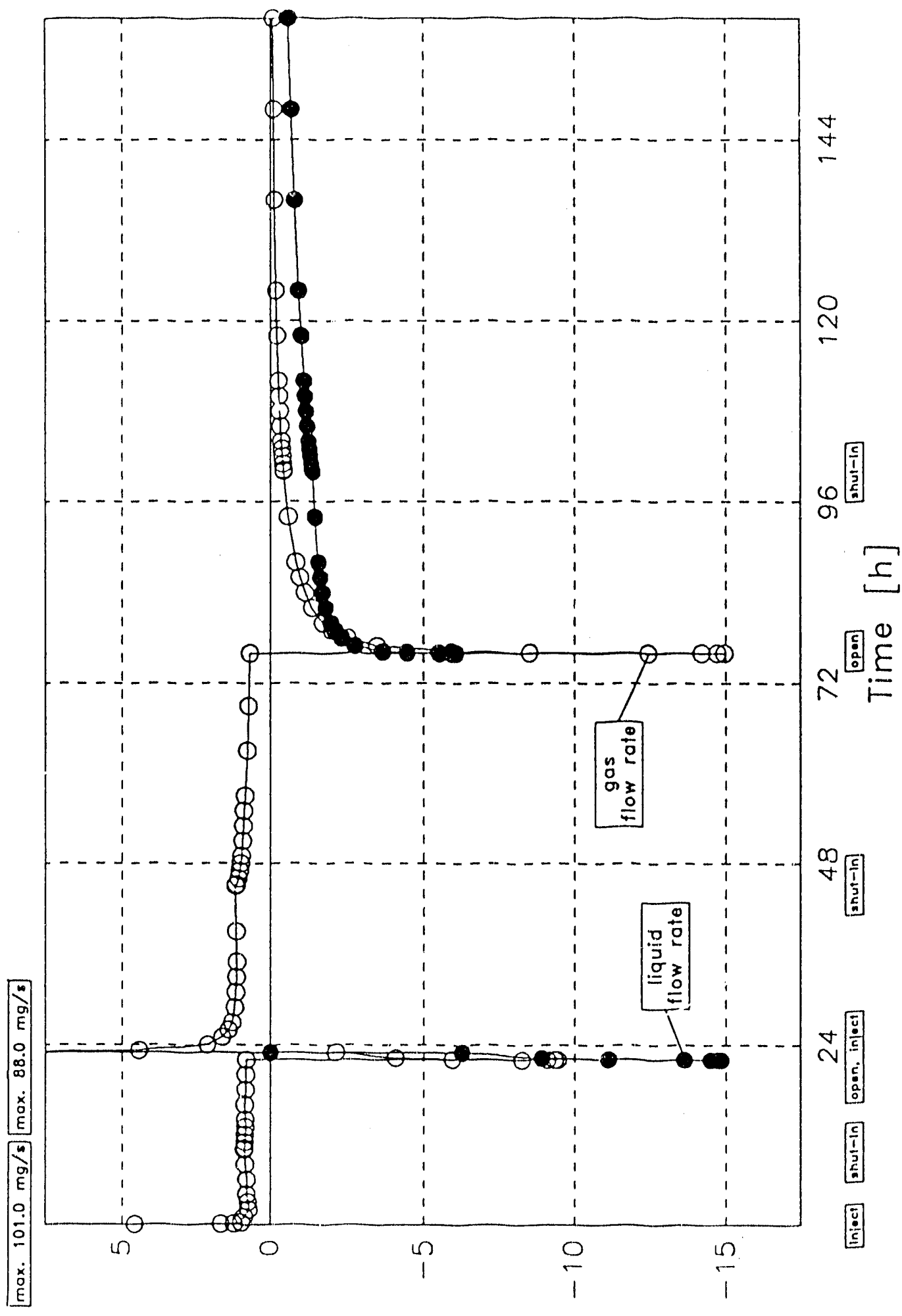

$[s / 6 u]$ afDd Molf

Figure 6: Predicted gas and water flow rates at BOFR 87.(0)1. 


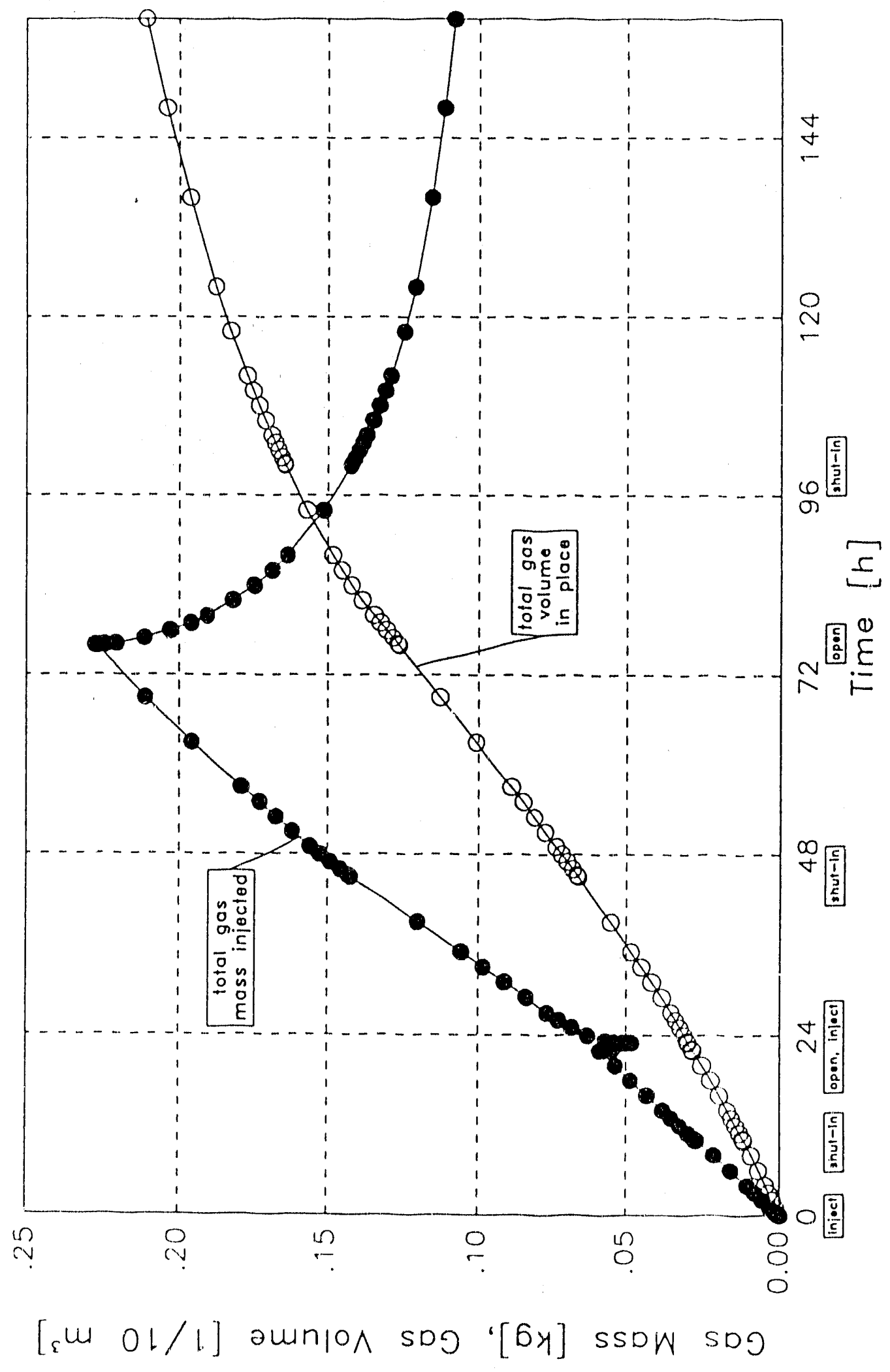

Figure 7: Predicted total gas mass and volume in place. 


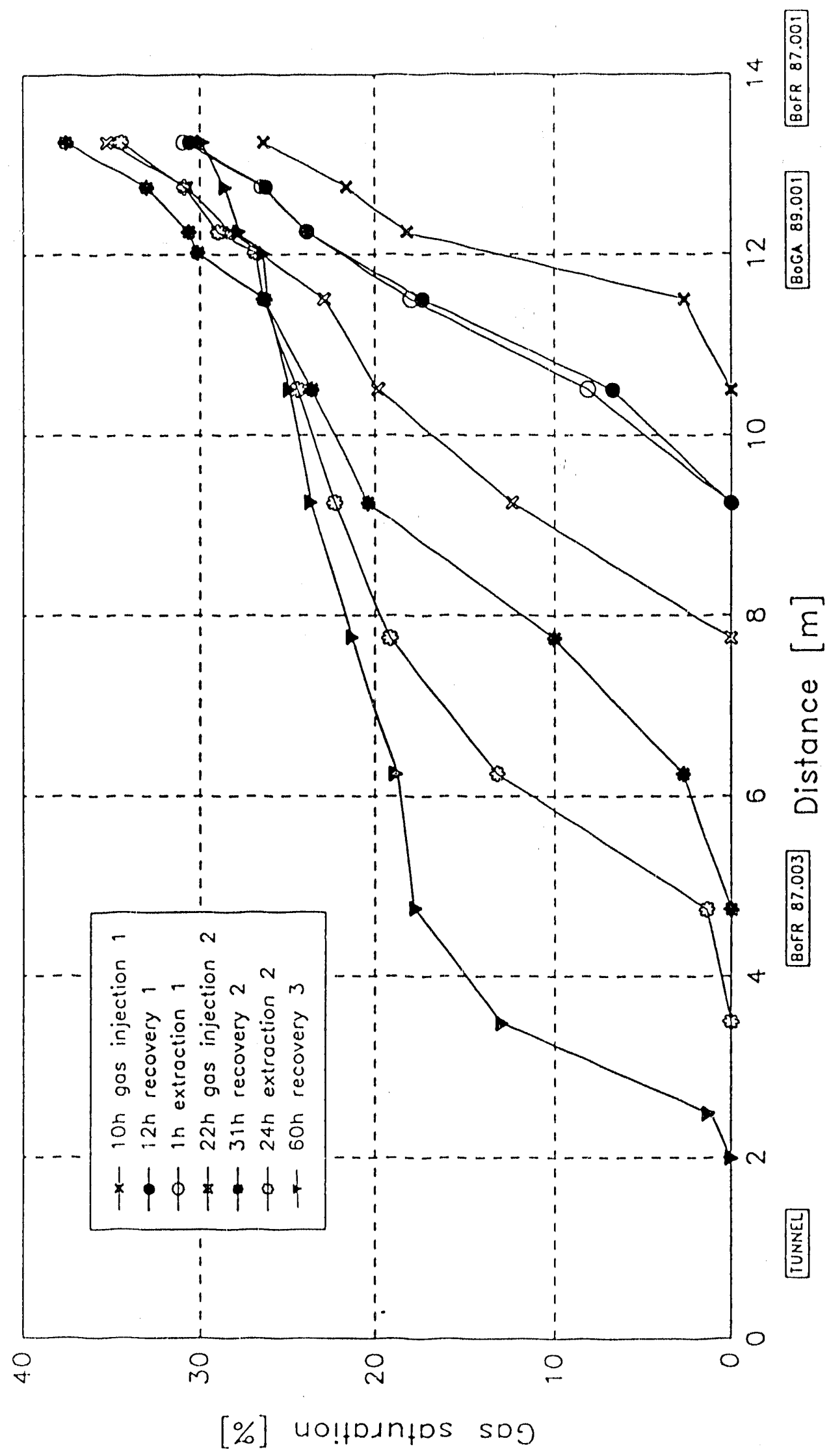

Figure 8: Predicted gas saturation along horizontal line between the tunnel and the injection well. 


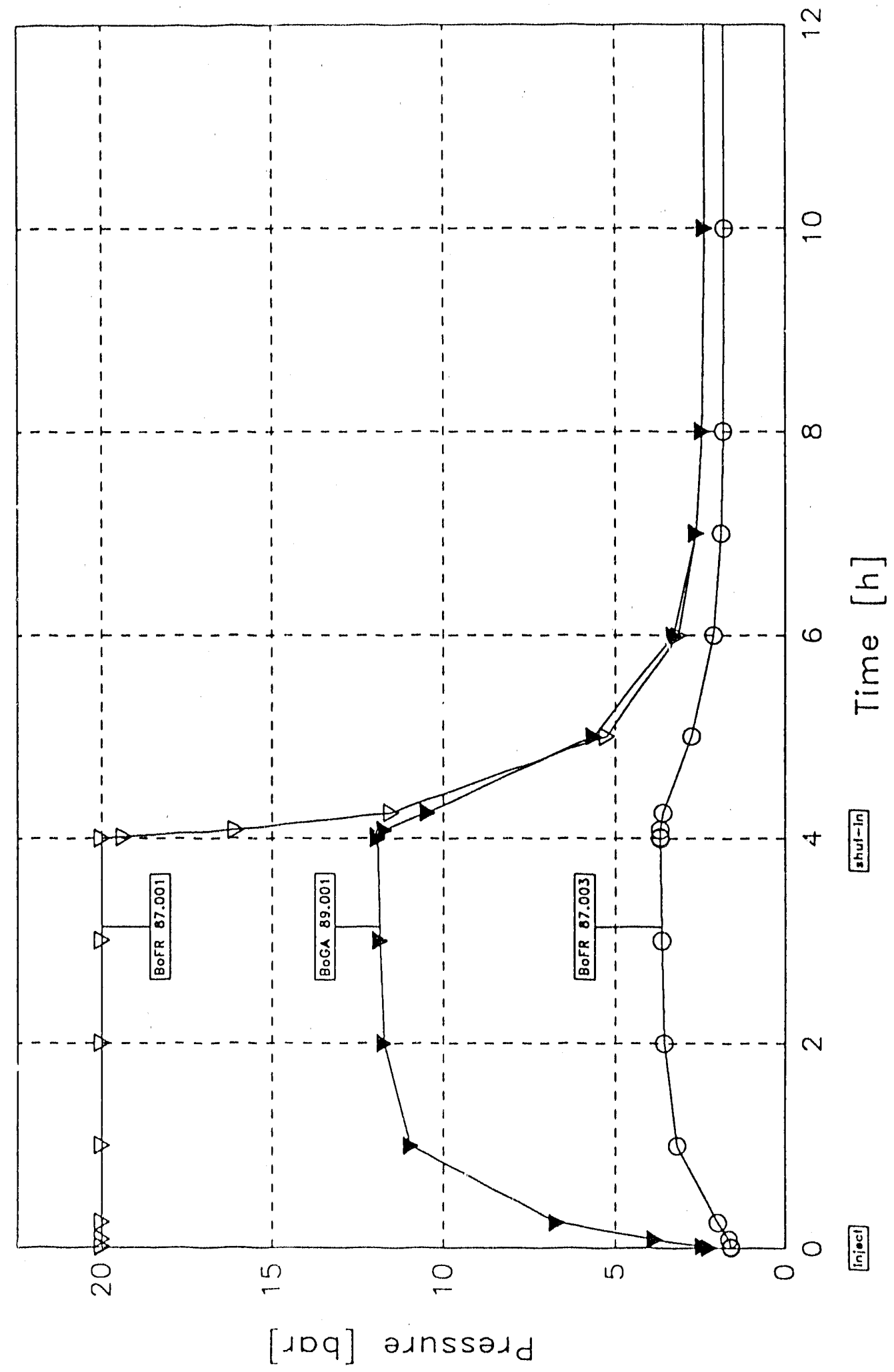

Figure 9: Initial hydraulic test: predicted pressure response. 


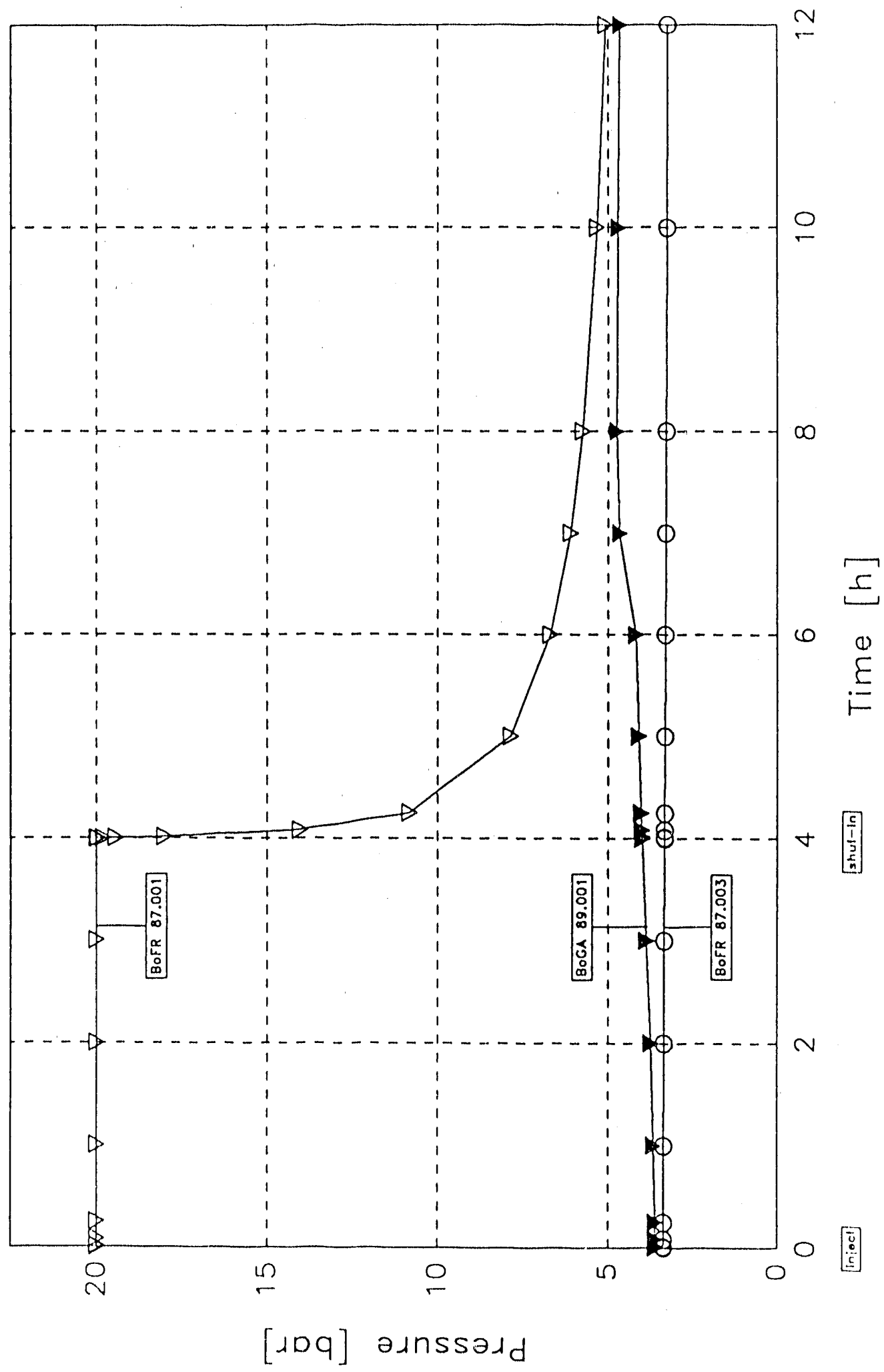

Figure 10: Final hydraulic test: predicted pressure response. 


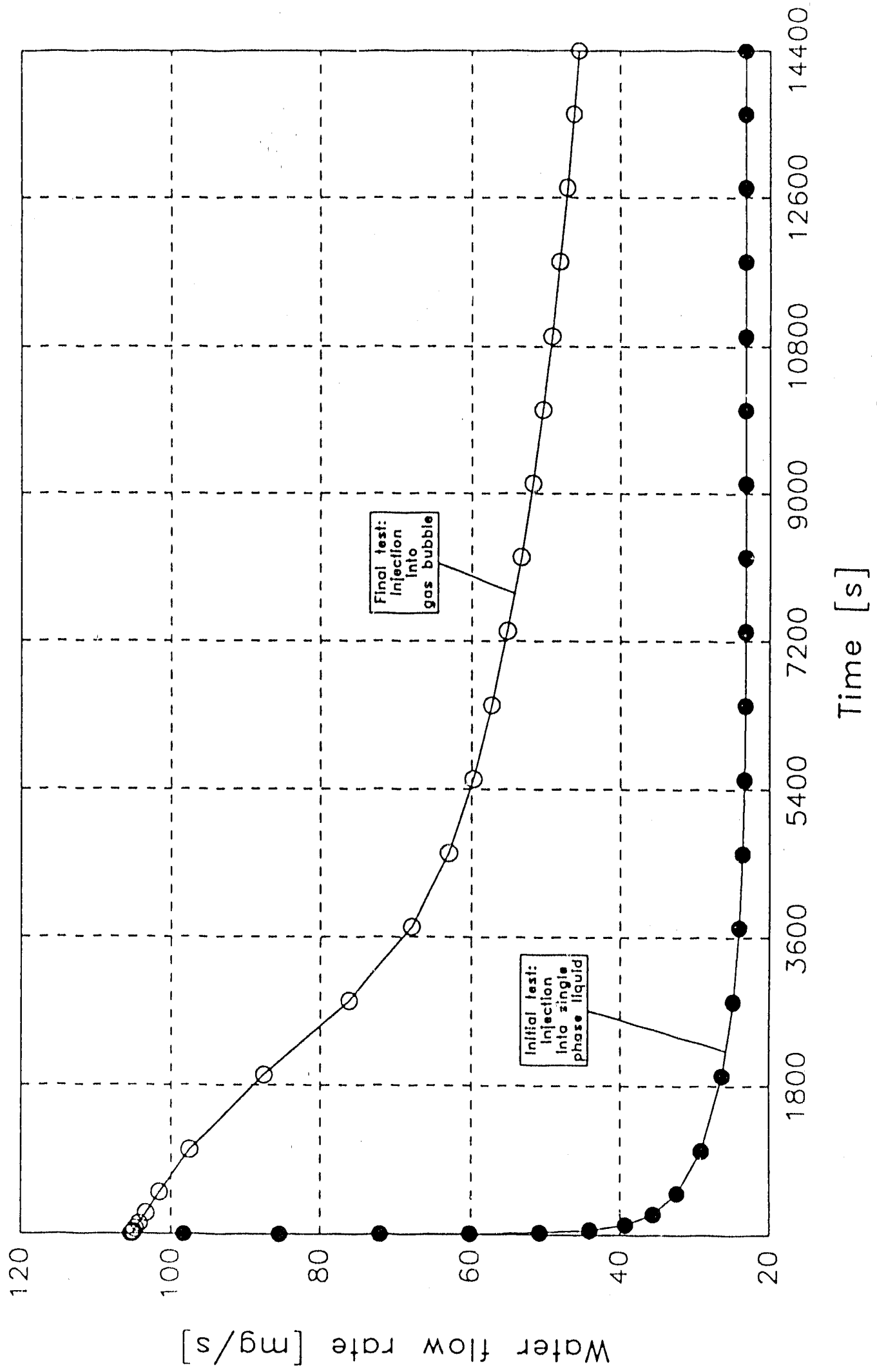

Figure 11: Predicted water flow rates during the initial and final hydraulic test. 


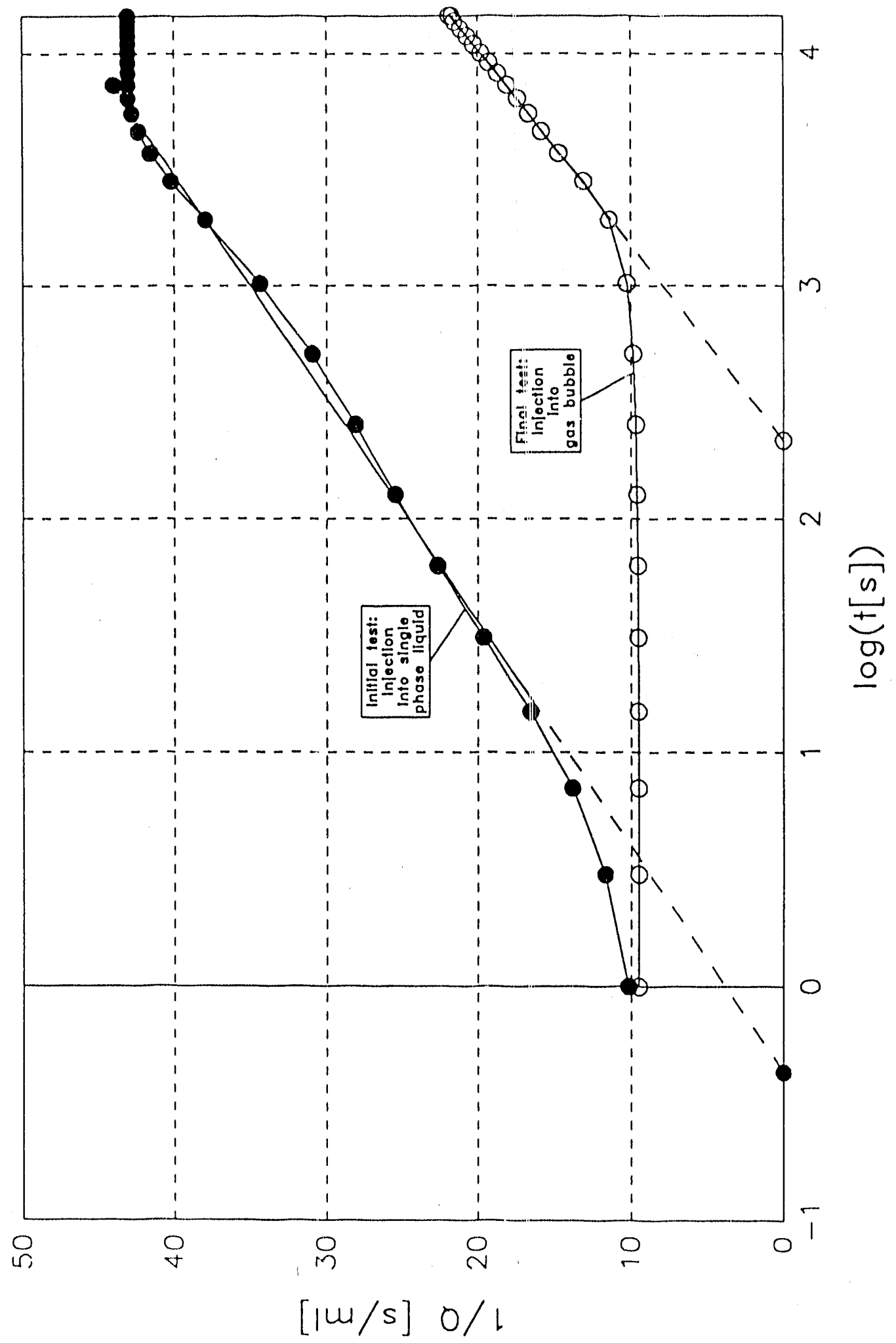

Figure 12: Jacob-Lohmann-plots of initial and firal hycraulic test. 


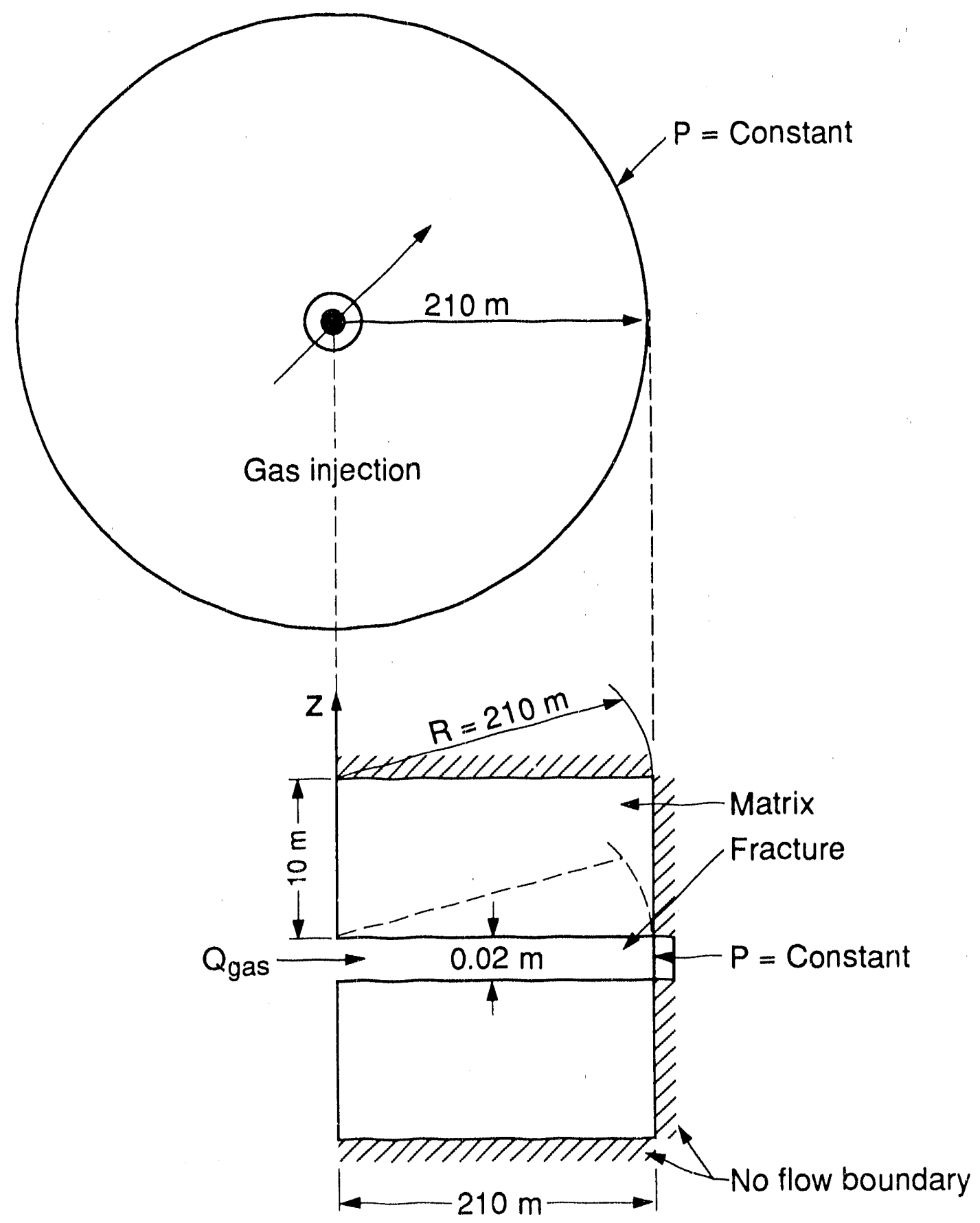

XBL 894-7555

Figure 13: Schematic of radial fracture-matrix flow problem. 


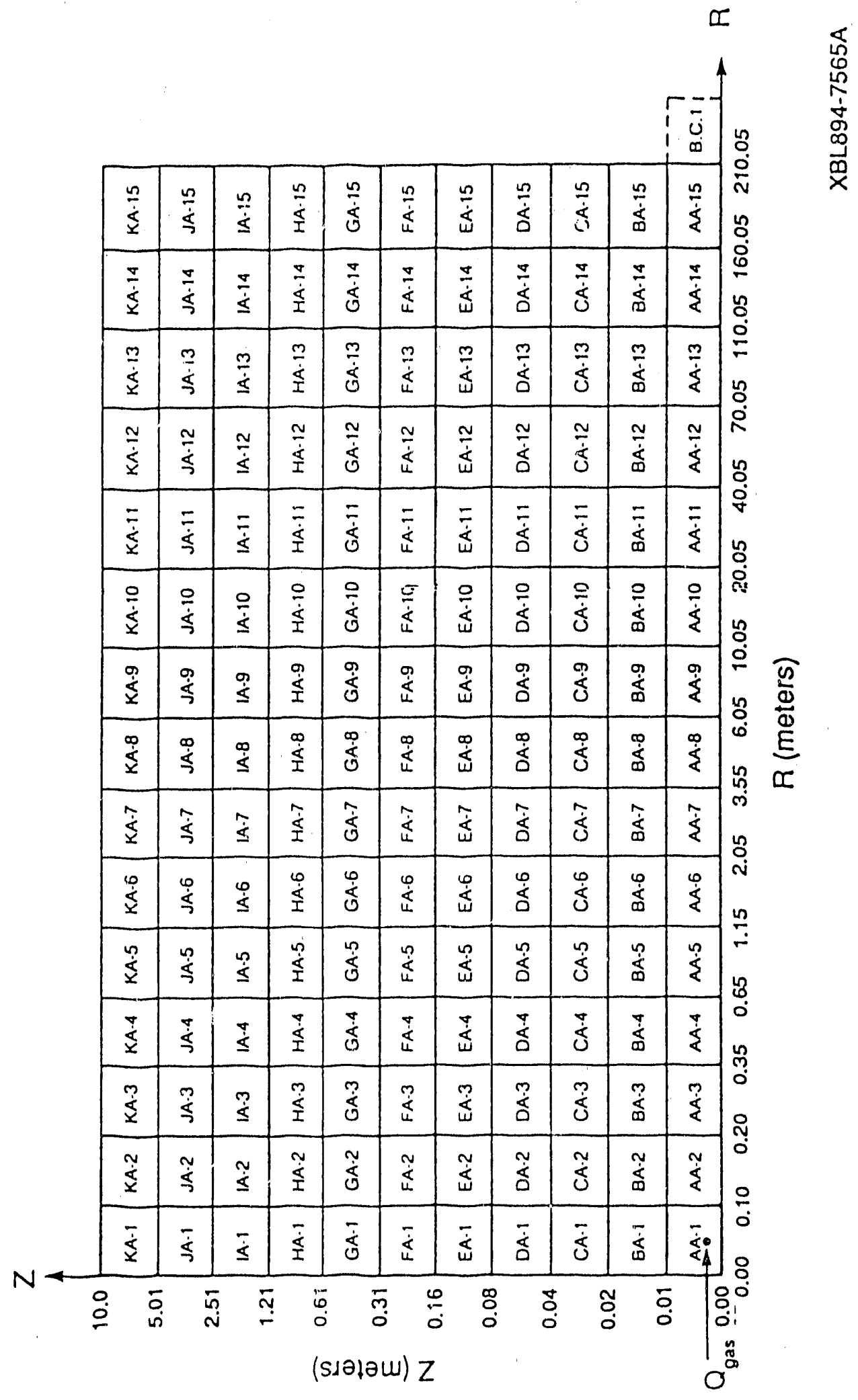

Figure 14: Computational grid for radial fracture-matrixy problem (not to scale). 


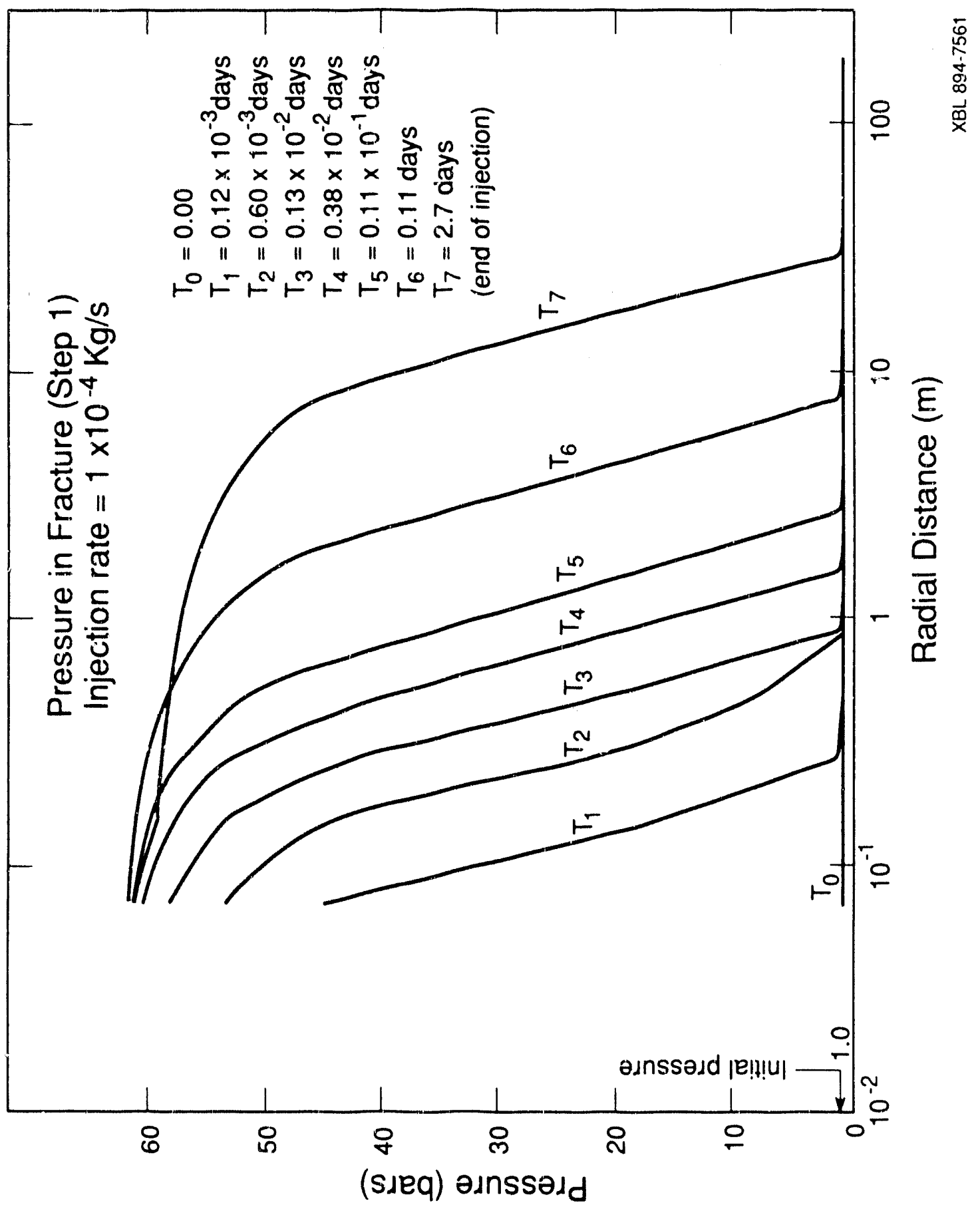

Figure 15: Gas pressures in fracture for different injection times (injection rate $Q=10^{-4}$ $\mathrm{kg} / \mathrm{s})$ 


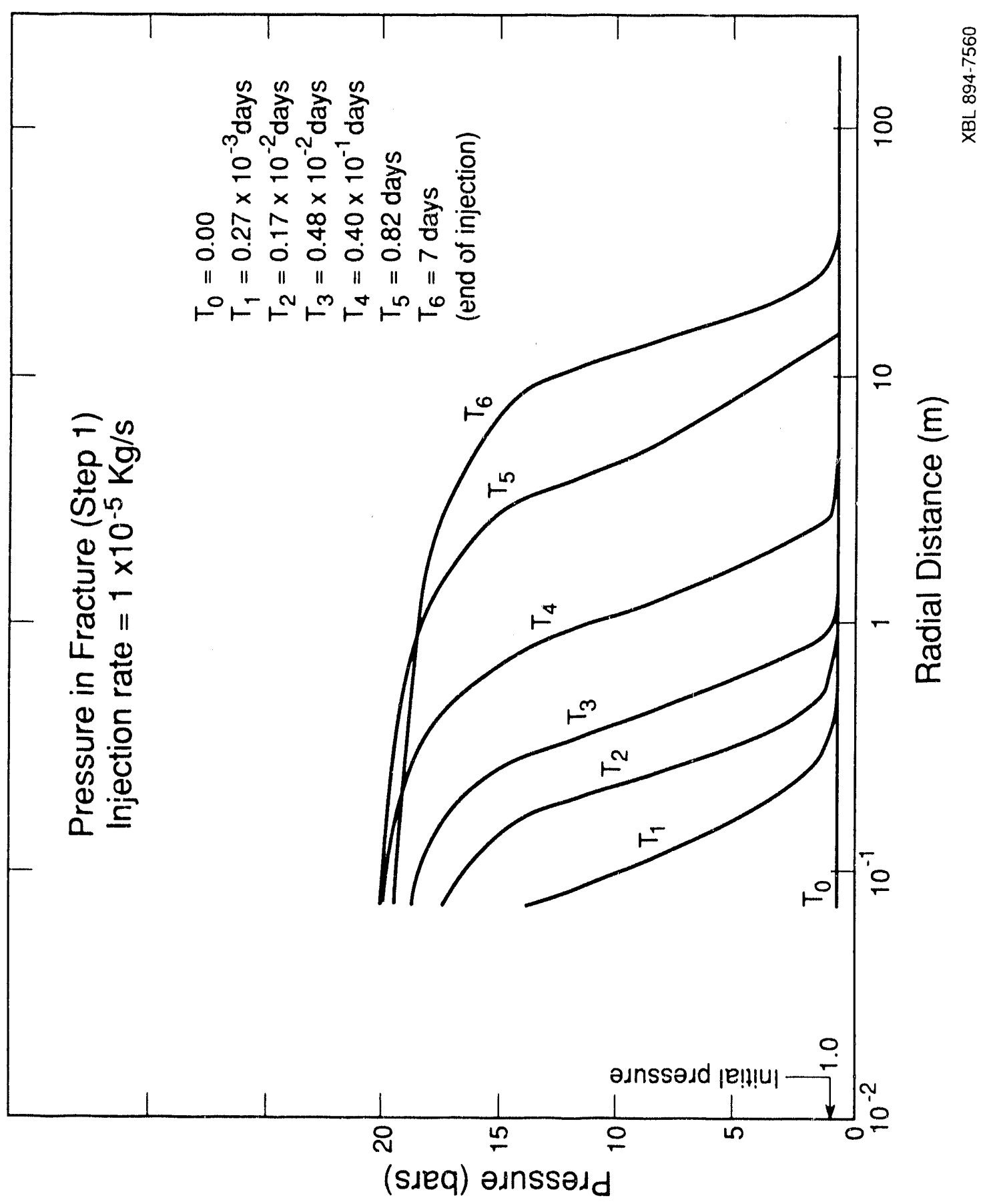

Figure 16: Gas pressures in fracture for different injection times (injection rate $Q=10^{-5}$ $\mathrm{kg} / \mathrm{s})$. 


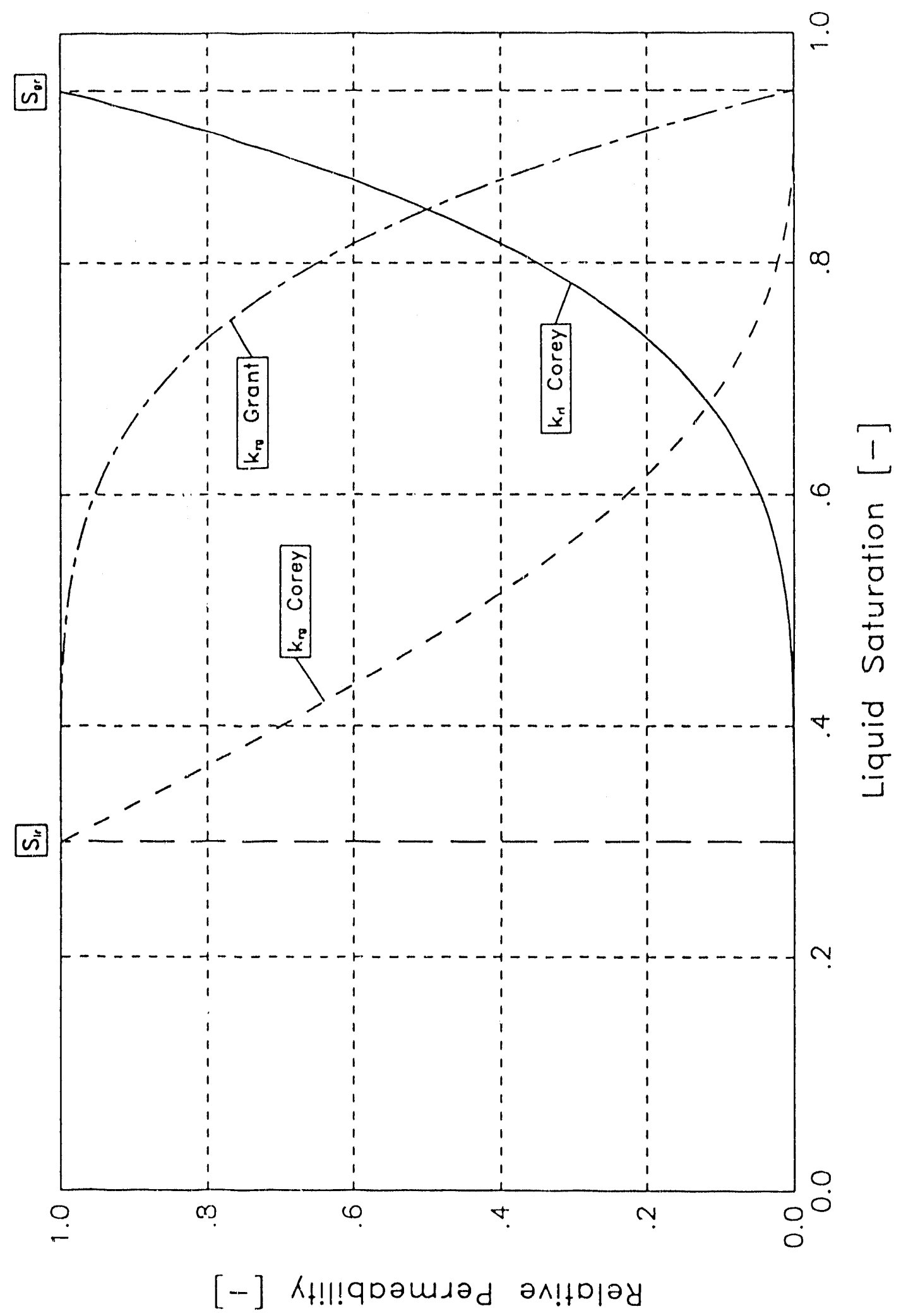

Figure 17: Relative pernieability functionis. 


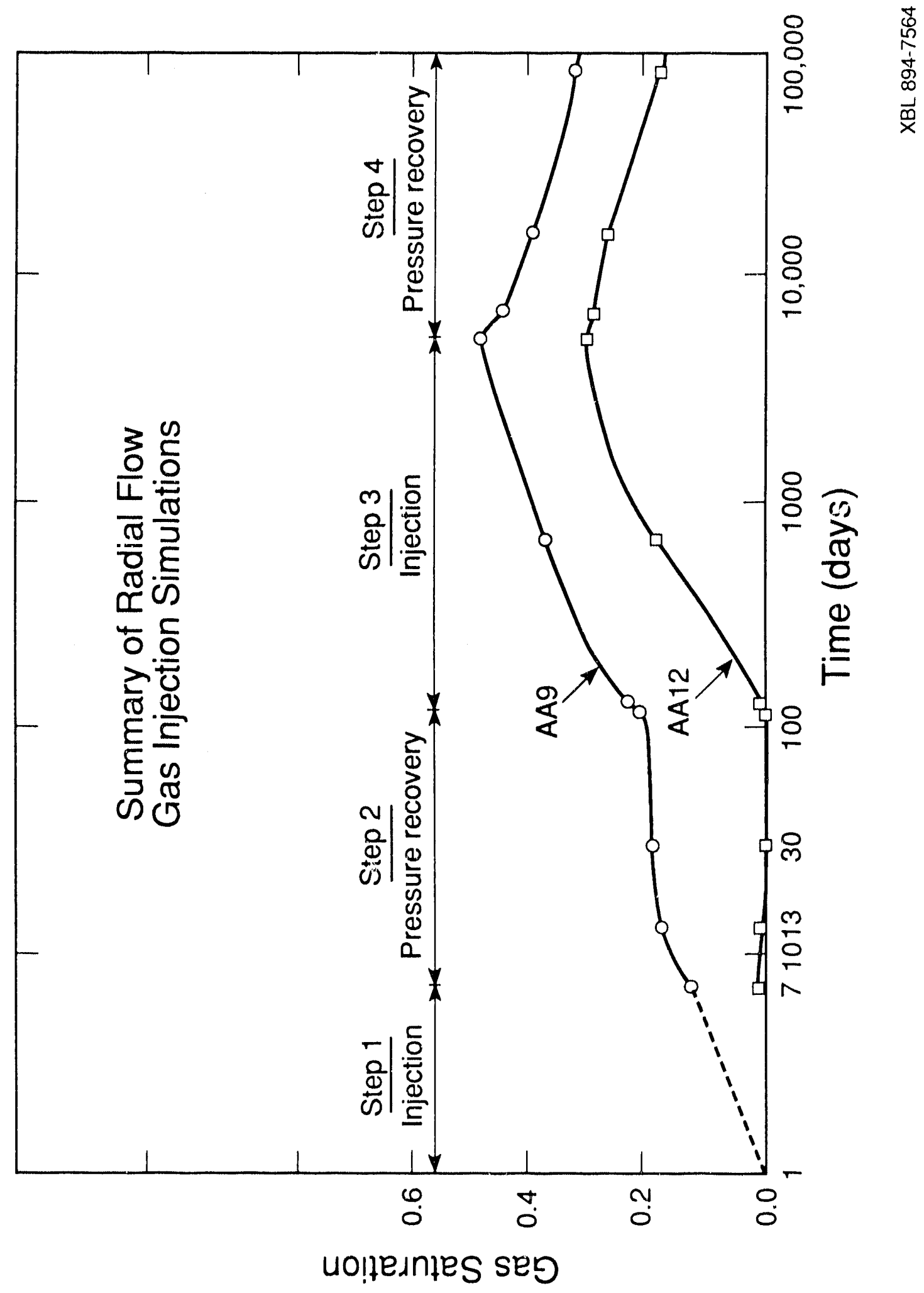

Figure 18: Gas, saturation vorsüs time for difficrent injectioui and iecovery periods. 


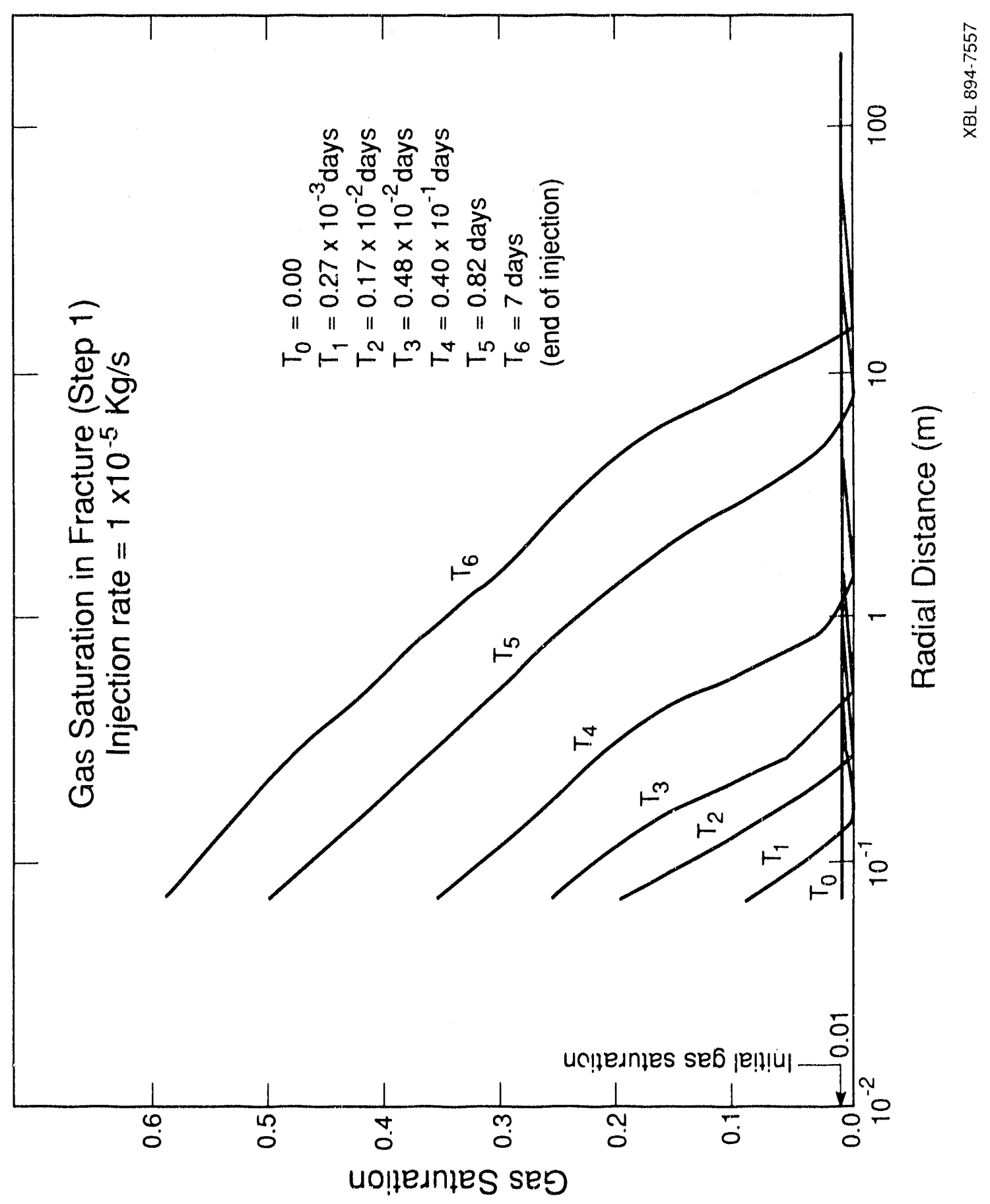

Figure 19: Gas saturation profilies in fractuie. 


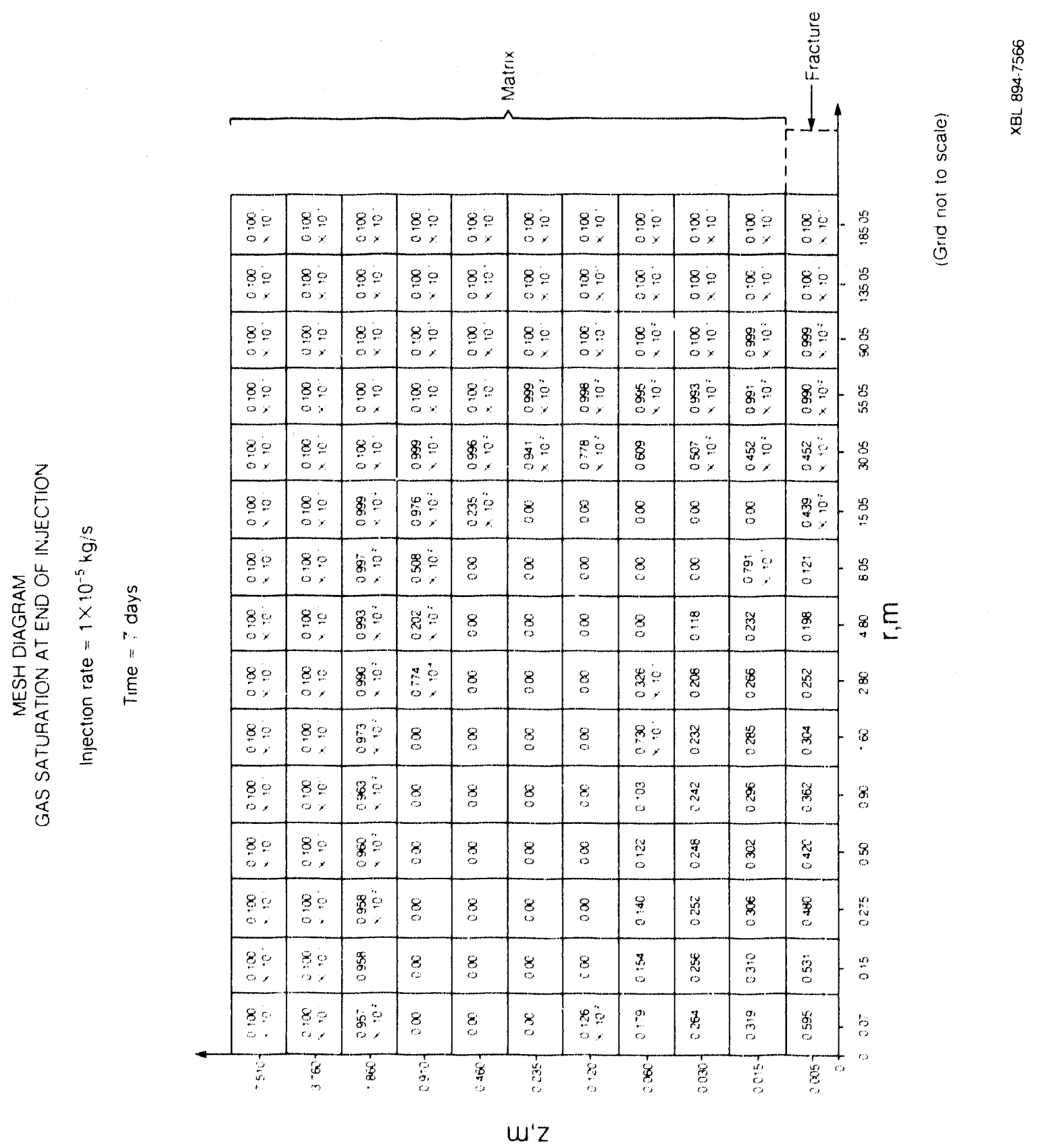

Figure 20: Gas saturation distribution at end of first seven-day injection period. 


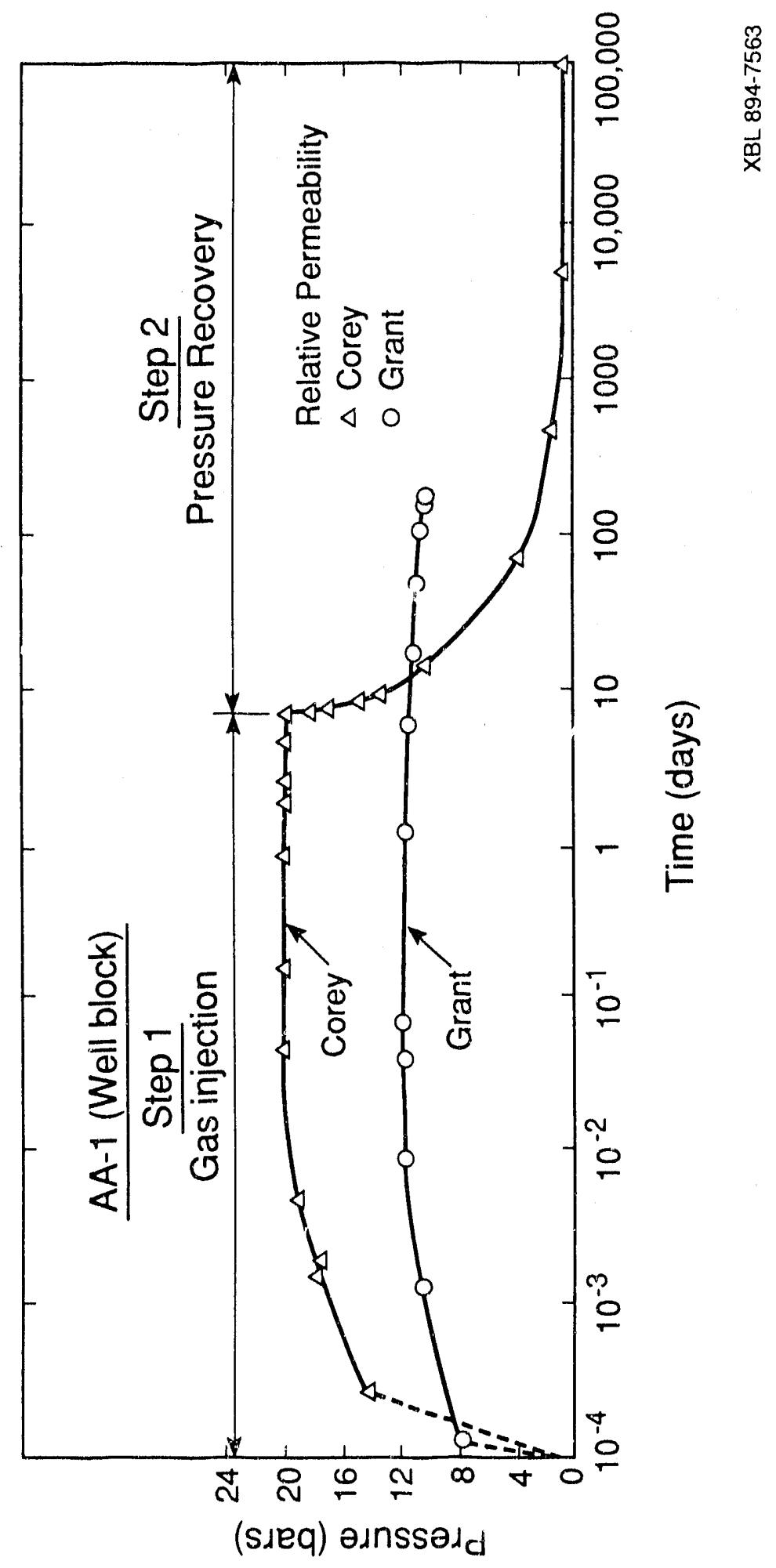

Figuire 21: Gas presssure verosus tinìe in the injection bluck. 


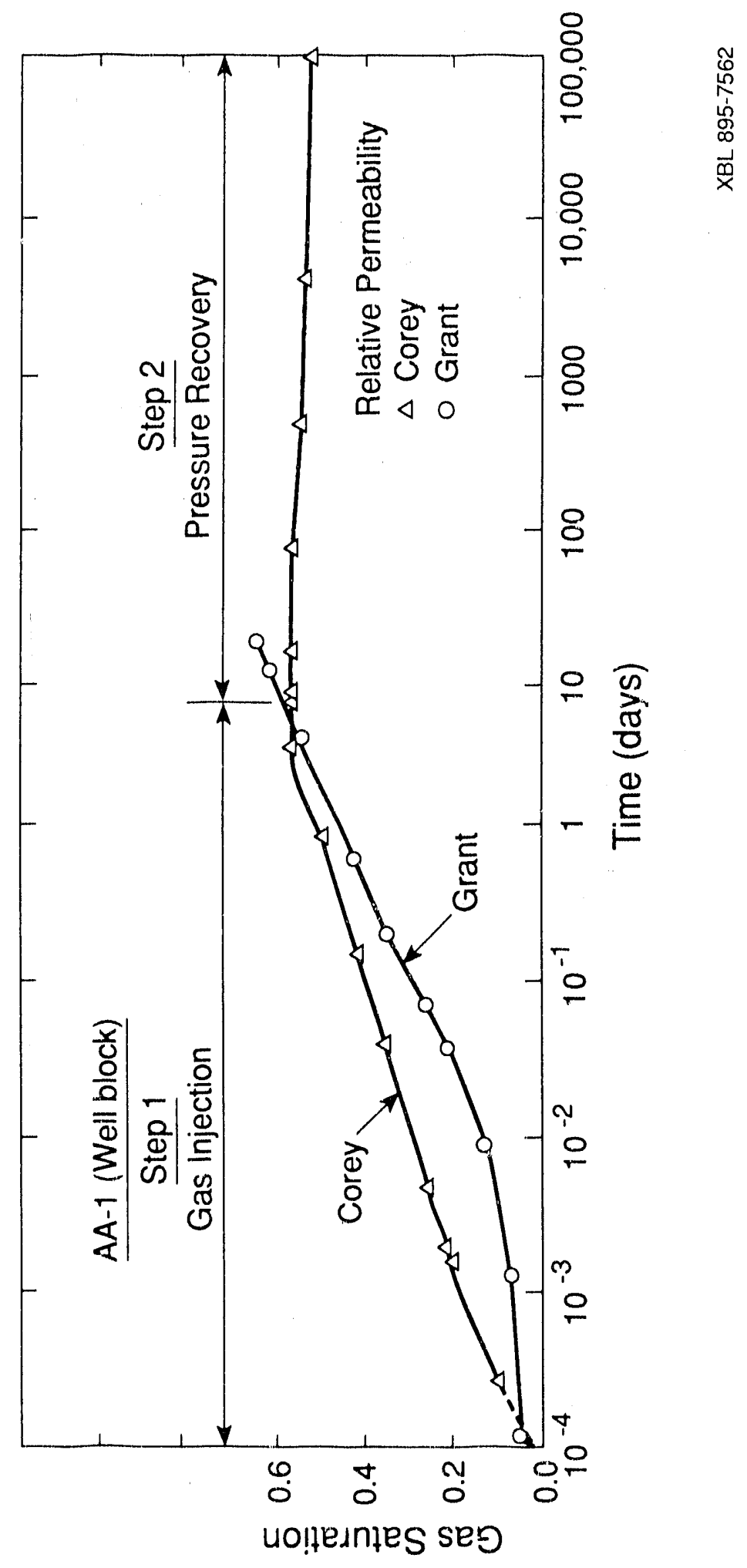

Figure 22. Gas saturation versus time in the injection biock. 


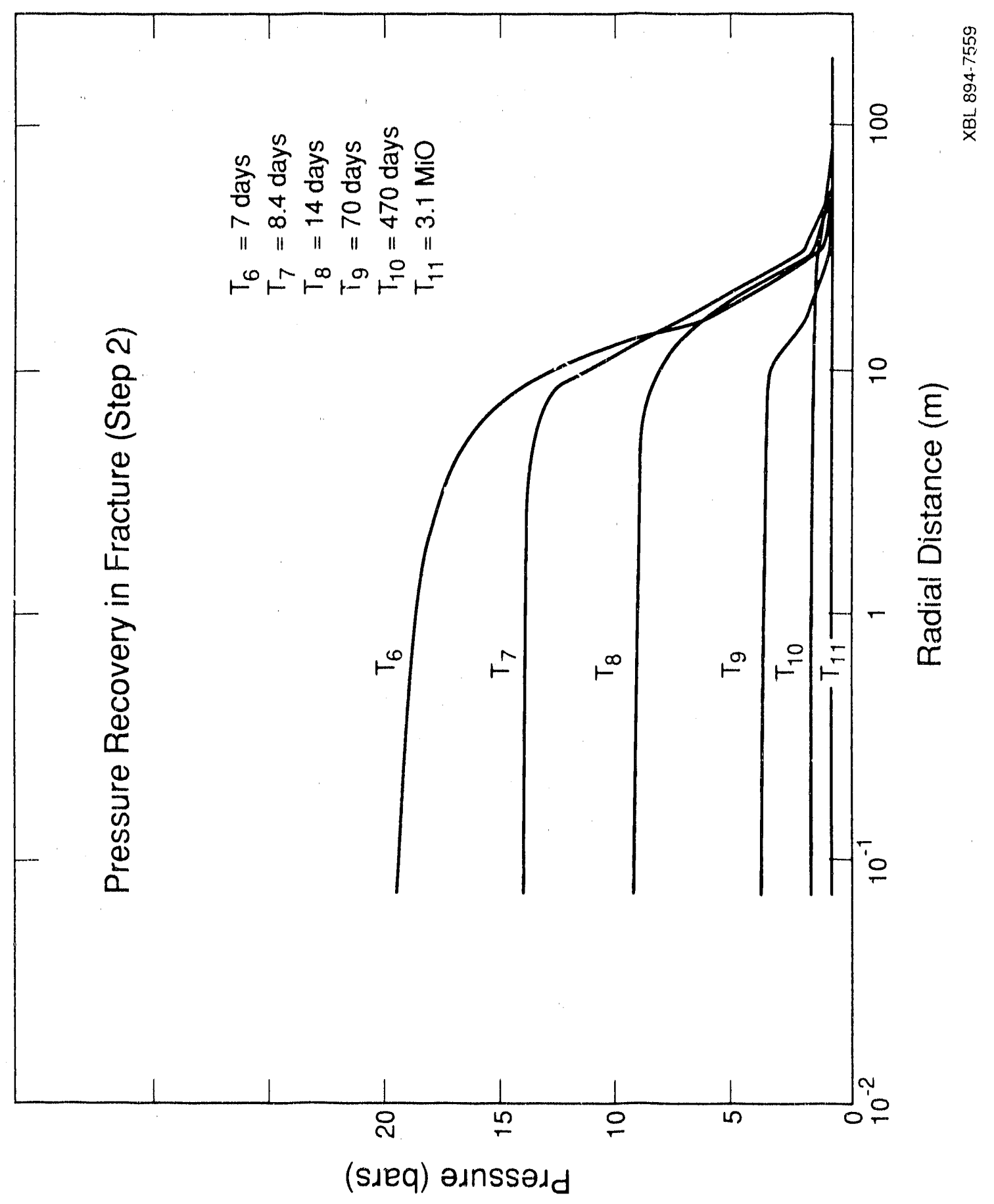

Figure 23: Gas pressure profiles in fracture during recovery, following seven-day injection period. 


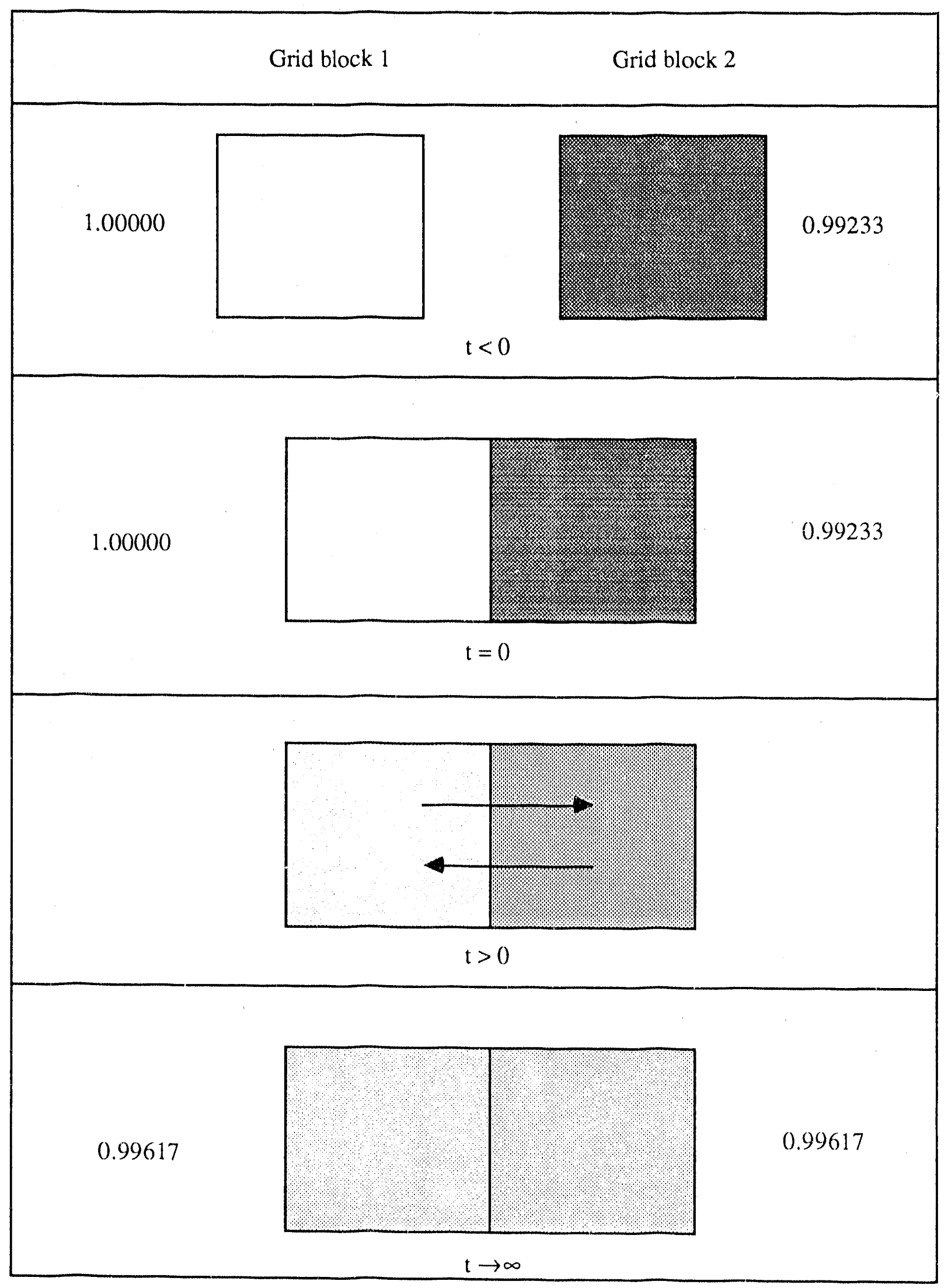

Figure 24: Binary diffusion experiment under single-phase conditions. 

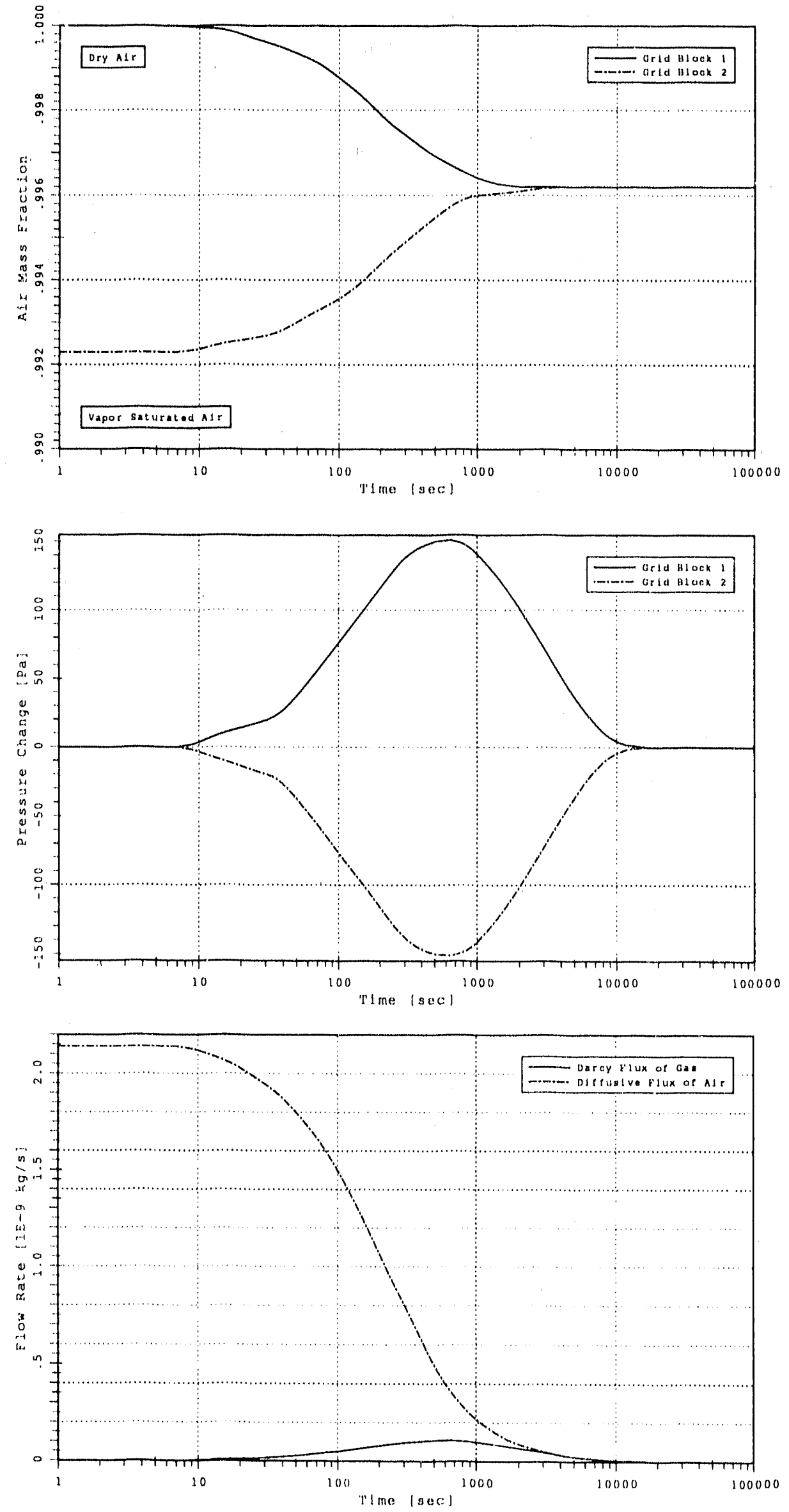

Figure 25: Binary diffusion experiment under single-phase conditions: Air mass fraction, pressure change and flow rates versus time. 


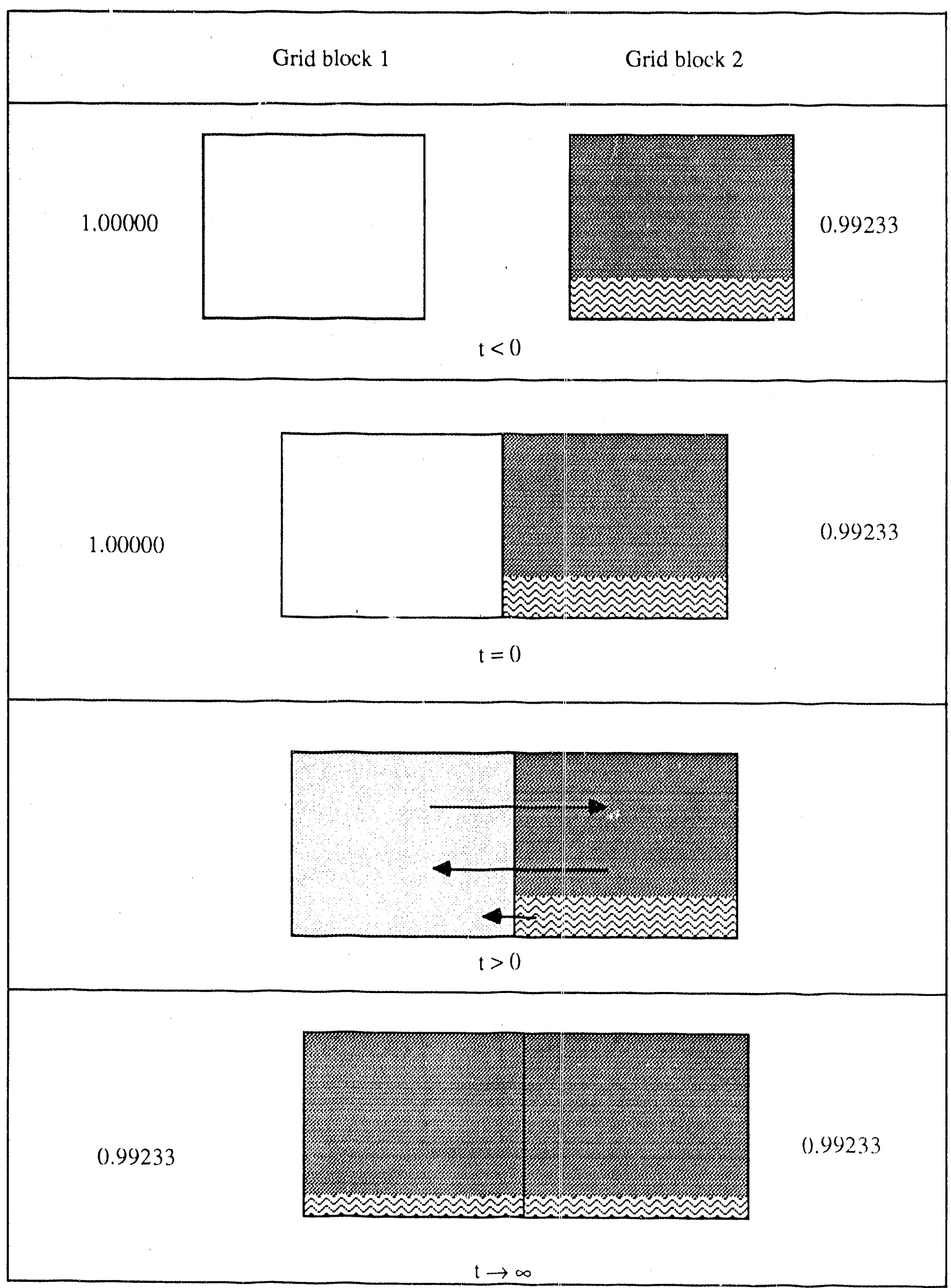

Figure $26:$ Binary diffusion experiment under two-phase conditions 

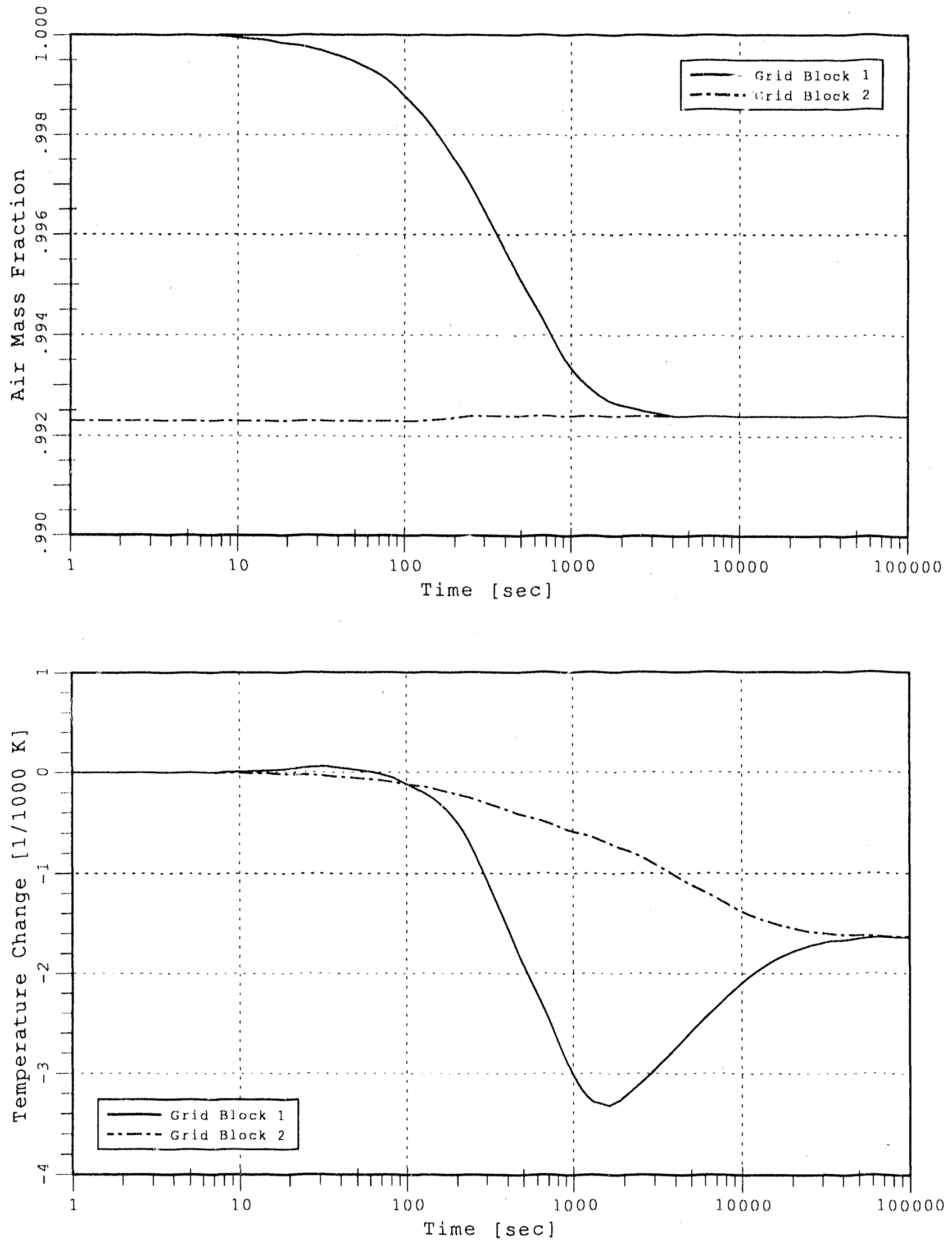

Figure 27a: Binary diffusion experiment under two-phase conditions:

Air mass fraction and temperature change versus time. 

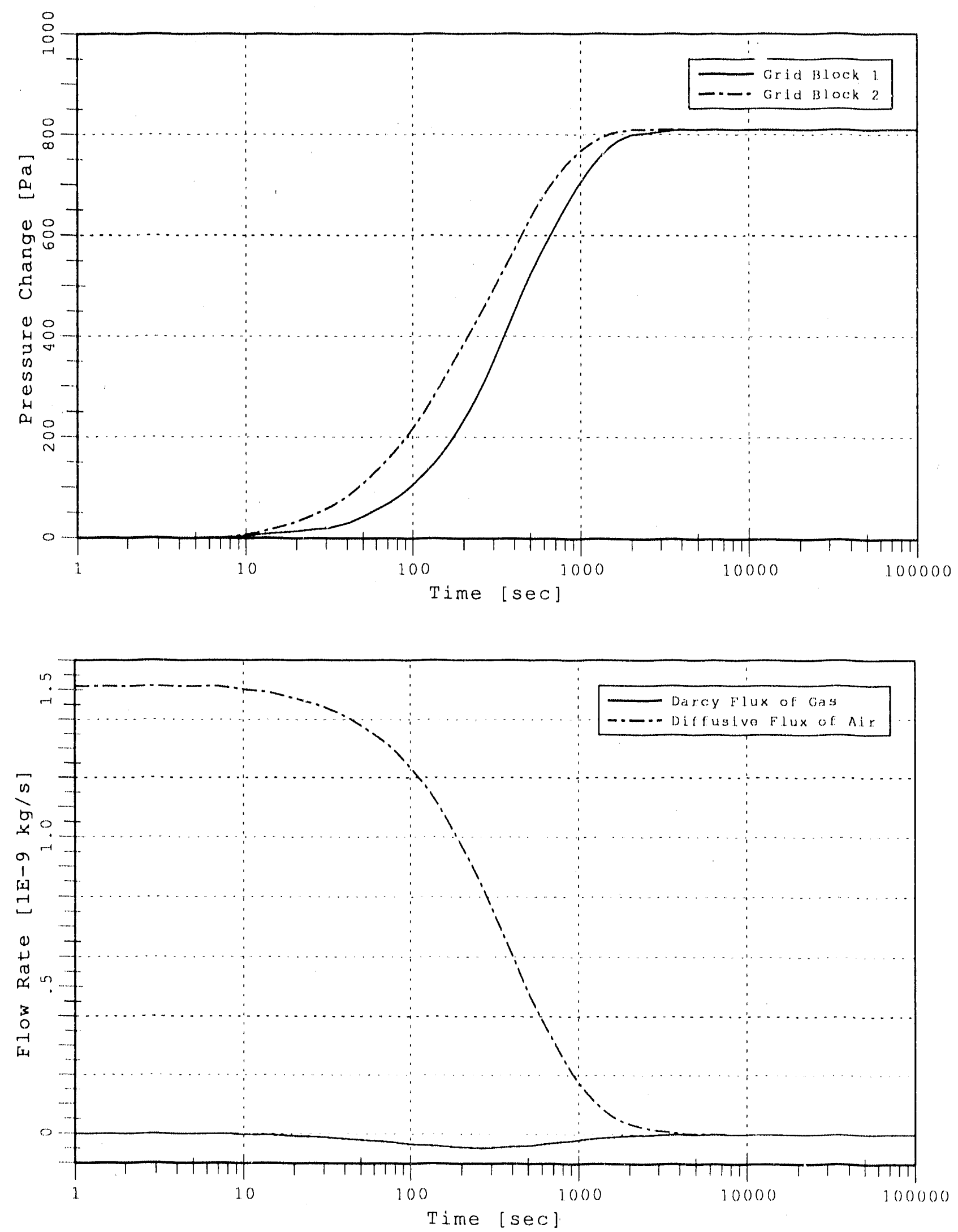

Figure 27b: Binary diffusion experiment under two-phase conditions: Pressure change and flow rates versus time. 

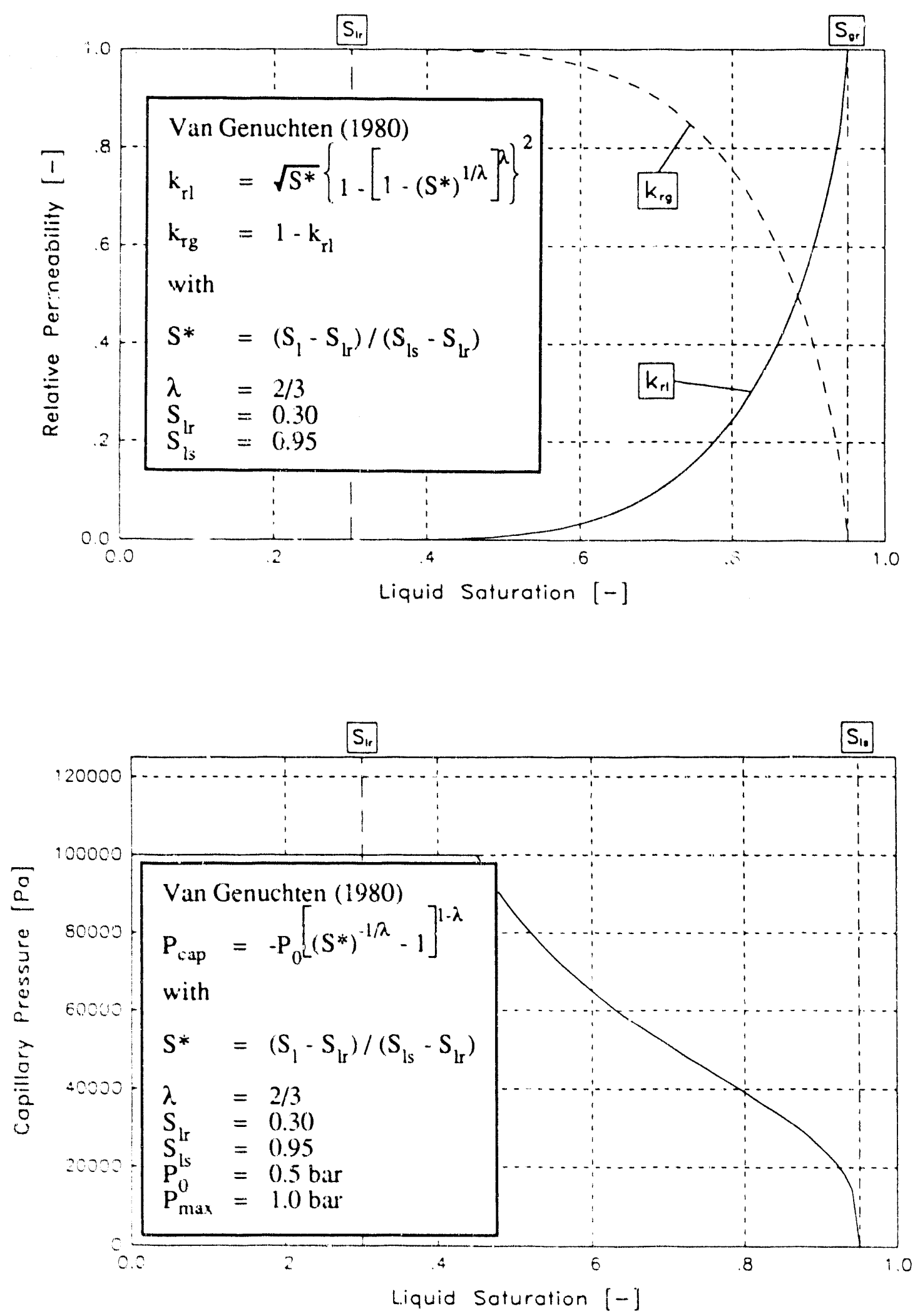

Figure 28: Kelative permeability an'd capillary pressure functions. 


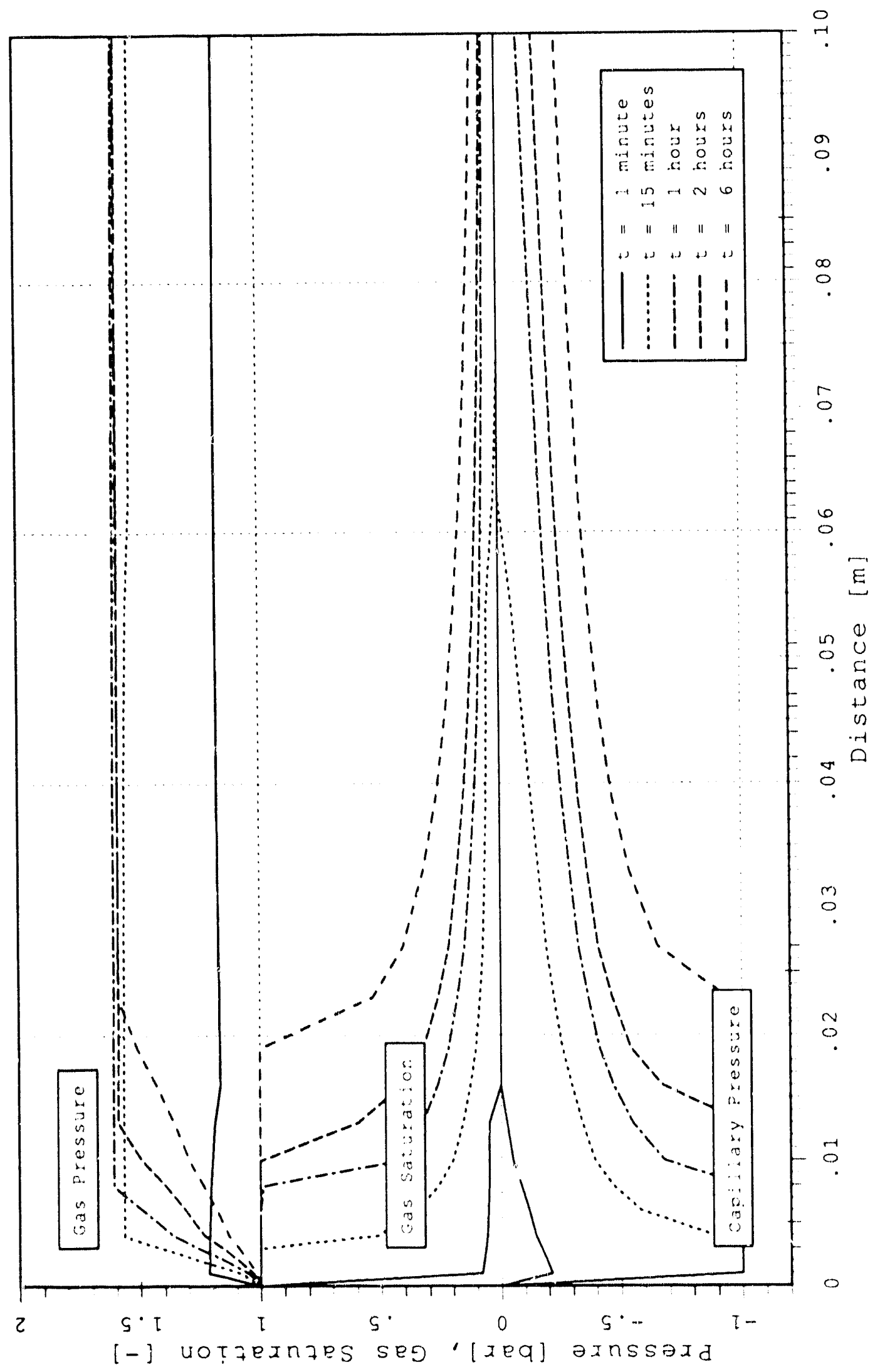

Figure 29: Gas pressure, gas saturation and capiiiary pressures proñies. 

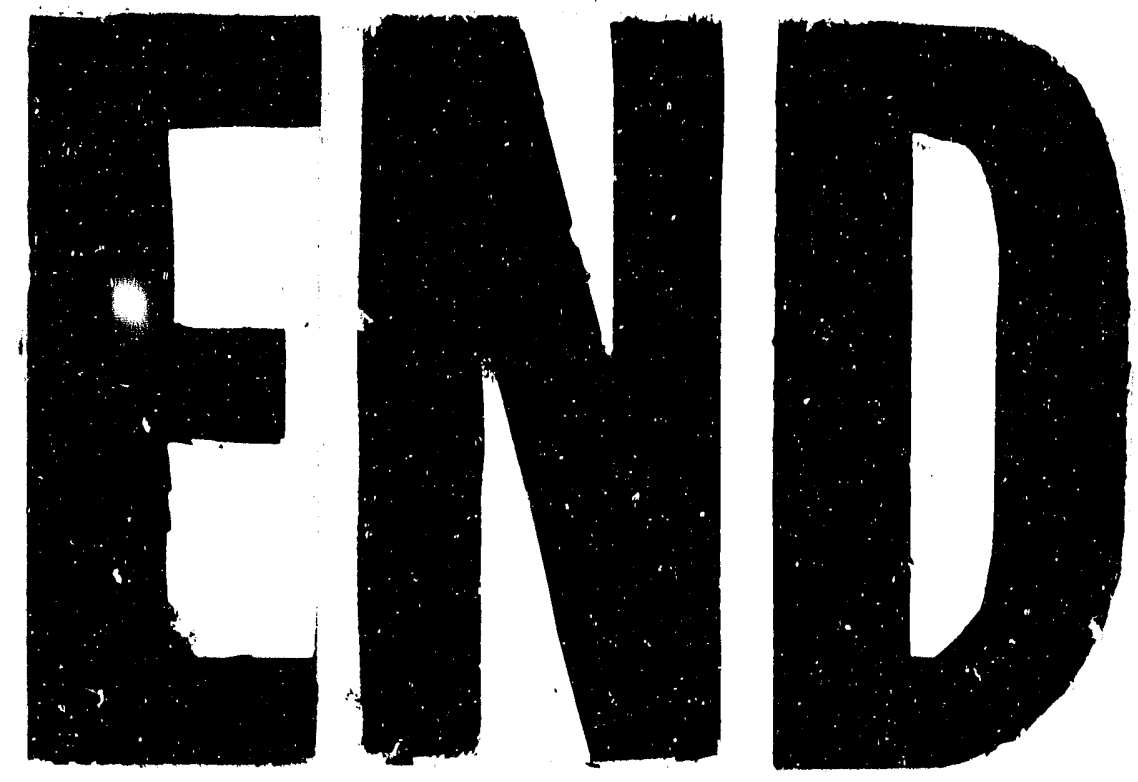

3
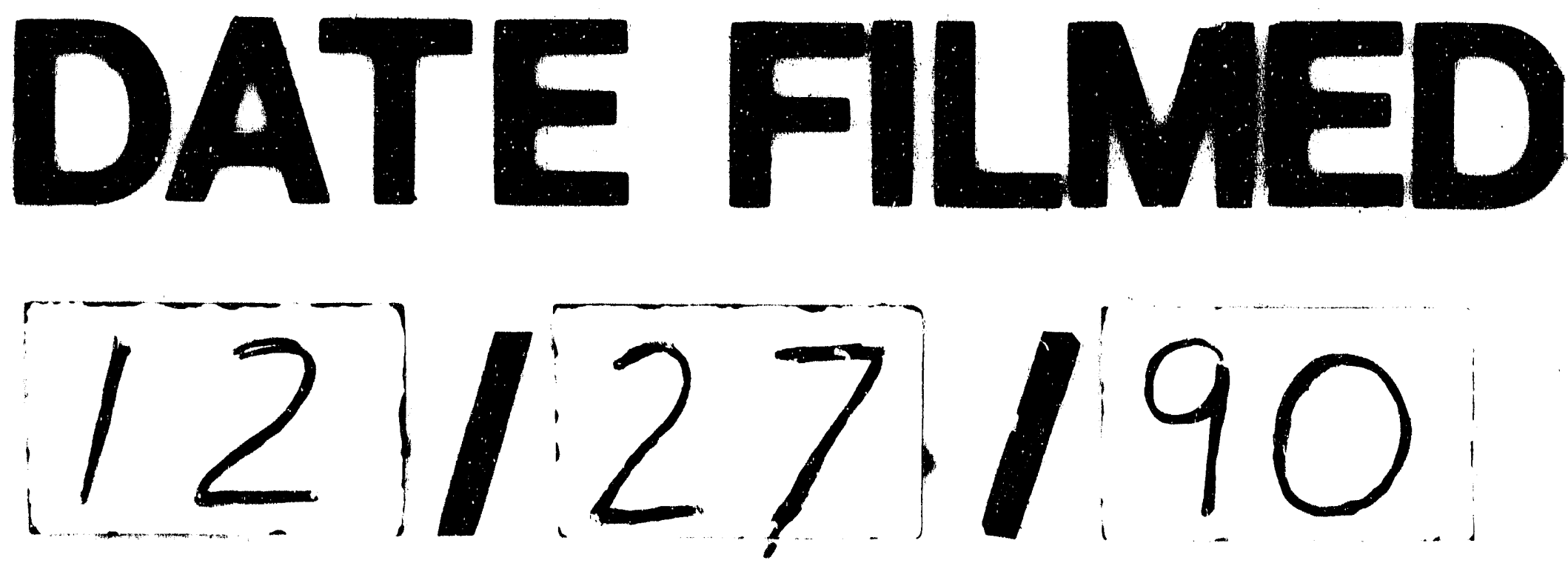
